\title{
Review of the genus Tylopus Jeekel, 1968, with descriptions of five new species from Thailand (Diplopoda, Polydesmida, Paradoxosomatidae)
}

\author{
Natdanai Likhitrakarn ${ }^{1, \dagger}$, Sergei I. Golovatch ${ }^{2, \ddagger}$, Rujiporn Prateepasen ${ }^{3, \S}$, \\ Somsak Panha',I
}

I Animal Systematics Research Unit, Department of Biology, Faculty of Science, Chulalongkorn University, Bangkok, 10330, Thailand. 2 Institute for Problems of Ecology and Evolution, Russian Academy of Sciences, Leninsky pr. 33, Moscow119071, Russia. 3 The Scientific and Technological Research Equipment Center, Chulalongkorn University,Bangkok, 10330, Thailand.

† urn:lsid:zoobank.org:author:46C52EE1-A383-4C86-BF97-39E07C195075

¥ urn:lsid:zoobank.org:author:71532F45-BDD5-415D-BC54-86256E5D5D4A

§ urn:lsid:zoobank.org:author:B003CBAC-C965-4BD1-A0D8-579AF9F8CCF4

| urn:lsid:zoobank.org:author:AC935098-D901-4F35-A414-4B0D4FE44E79

Corresponding authors: Sergei I. Golovatch (sgolovatch@yandex.ru), Somsak Panha (somsakp@sc.chula.ac.th)

Academiceditor:RobertMesibov|Received 19November2010|Accepted11December2010|Published 17December 2010

urn:lsid:zoobank.org:pub:47A90C15-3749-4451-B89E-394DBC676D00

Citation: Likhitrakarn N, Golovatch SI, Prateepasen R, Panha S (2010) Review of the genus Tylopus Jeekel, 1968, with descriptions of five new species from Thailand (Diplopoda, Polydesmida, Paradoxosomatidae). Advances in the systematics of Diplopoda III. ZooKeys 72: 23-68. doi: 10.3897/zookeys.72.744

\begin{abstract}
The genus Tylopus currently contains 41 species, all keyed and mapped, including five new from northern Thailand: T. bispinosus sp. n., T. grandis sp. n., T. extremus sp. n., T. veliger sp. n. and T. parajeekeli sp. n. Species of Tylopus are predominantly forest-dwellers, especially in montane habitats where up to 9-10 species can coexist per faunule. We expect many more congeners to be discovered in future, in particular from poorly or relatively poorly prospected regions such as Laos (only two species recorded), Cambodia (no species yet), Vietnam (a few species), Myanmar (a few species) and southern China (one species only). Because the genus is so species-rich and as yet so poorly sampled, a phylogenetic analysis of Tylopus would be premature.
\end{abstract}

\section{Keywords}

millipede, Tylopus, taxonomy, new species, key, Thailand

Copyright N. Likhitrakarn et al. This is an open access article distributed under the terms of the Creative Commons Attribution License, which permits unrestricted use, distribution, and reproduction in any medium, provided the original author and source are credited. 


\section{Introduction}

Tylopus Jeekel, 1968, is one of the largest and most common genera in the millipede family Paradoxosomatidae in Southeast Asia and adjacent parts of southern China. When last reviewed (Golovatch and Enghoff 1993), it comprised 35 species. Only one more has since been added (Golovatch 1995), thus bringing the number of known species to 36 .

The present paper provides a new review of Tylopus, based on numerous recently collected samples which also include five new species from northern Thailand. These new species are described herein, another seven are redescribed based on additional samples, and a new key is provided to incorporate all 41 species currently known to comprise Tylopus. We are confident that many more species in this genus will be found in future, given that several large areas in Laos, Myanmar, Cambodia and Vietnam, as well as in southern China, are as yet poorly sampled for millipedes. At present, perhaps only Thailand can be regarded as relatively well prospected, and has already yielded 26 Tylopus species.

\section{Material and methods}

New material derives from several provinces of northern Thailand taken between 2006 and 2010. All holotypes, as well as most of the paratypes and non-types, are in the collection of the Museum of Zoology, Chulalongkorn University, Bangkok, Thailand (CUMZ), some duplicates also being donated to the collections of the Natural History Museum of Denmark, University of Copenhagen, Denmark (ZMUC), and of the Zoological Museum, State University of Moscow, Russia (ZMUM), as indicated in the text.

Coloration was photographed in the laboratory (both live and alcohol material) for all of the encountered species. Material was then fixed, preserved in $75 \%$ ethanol and studied in the lab using a standard Olympus stereomicroscope. Scanning electron micrographs (SEM) were taken using a JEOL, JSM-5410 LV microscope. After SEM examination of the gonopods, they were returned to alcohol.

\section{Taxonomic part}

\section{Checklist}

The following species of Tylopus have heretofore been described, all arranged in alphabetic order and supplied with geographic details:

T. affinis Golovatch \& Enghoff, 1993 - Thailand, Chiang Mai Province, Doi Suthep National Park, Doi Pui summit, 1650 m; Doi Inthanon National Park, Mae Chaem road, $1700 \mathrm{~m}$; same locality, main road, $1900 \mathrm{~m}$. 
T. allorugosus Golovatch \& Enghoff, 1993 - Thailand, Chiang Mai Province, Doi Inthanon National Park, SiriphumWaterfall, 1300-1400 m; same locality, ca 1600 m; same locality, Mae Chaem road, $1700 \mathrm{~m}$; same locality, main road, $1900 \mathrm{~m}$; same locality, main road, 2200 m; same locality, 2200-2500 m; Doi Suthep National Park, Doi Pui summit, $1650 \mathrm{~m}$.

T. amicus Golovatch \& Enghoff, 1993 - Thailand, Chiang Mai Province, Doi Pha Hom Pok National Park, northwest of Fang, 1550-1750 m.

T. asper Golovatch \& Enghoff, 1993 - Thailand, Chiang Mai Province, Doi Inthanon National Park, $1500 \mathrm{~m}$.

T. baenzigeri Golovatch \& Enghoff, 1993 - Thailand, Chiang Mai Province, Doi Suthep National Park, Doi Pui-Chang Khian, 1400 m; same locality, 1400-1500 m; Doi Suthep National Park, near stream, $1100 \mathrm{~m}$.

T. coriaceus Golovatch \& Enghoff, 1993 - Thailand, Chaiyaphum Province, Khon San District, Phu Kheio, $16^{\circ} 22^{\prime} \mathrm{N}, 101^{\circ} 34^{\prime} \mathrm{E}, 1000 \mathrm{~m}$.

T. crassipes Golovatch, 1984 - Vietnam, Lao cai Province, O quy ho, near Sa pa, 1900 $\mathrm{m}$; same locality, near stream, $1950 \mathrm{~m}$.

T. degerboelae Golovatch \& Enghoff, 1993 - Thailand, Chiang Mai Province, Doi Suthep National Park, forest near stream, 1000 m; same locality, Doi Pui road, $1000 \mathrm{~m}$; same locality, $1100 \mathrm{~m}$; same locality, evergreen forest, $1300 \mathrm{~m}$; same locality, evergreen forest, $1400 \mathrm{~m}$; same locality, $1450 \mathrm{~m}$; same locality, $1500 \mathrm{~m}$; Doi Inthanon National Park, 1500 m; same locality, main road, 1600 m; Doi Chiang Dao, limestone area.

T. doriae (Pocock, 1895) - east-central Myanmar, Yado, 1000-1400 m, Bia-po, 10001200 m, Meteleo, 900-1200 m; Puepoli, 900-1200 m; Thailand, Chiang Mai Province, Doi Suthep National Park, 1400-1500 m.

T. granulatus Golovatch, 1984 - Vietnam, Ninh binh Province, Cuc Phuong Nature Reserve, forest.

T. haplorugosus Golovatch \& Enghoff, 1993 - Thailand, Chiang Mai Province, Doi Inthanon National Park, main road, $1900 \mathrm{~m}$.

T. hilaris (Attems, 1937) - Vietnam, Bana, $1500 \mathrm{~m}$.

T. hilaroides Golovatch, 1984 - Vietnam, Ninh binh Province, Cuc Phuong Nature Reserve, forest.

T. hoffmani Golovatch \& Enghoff, 1993 - Thailand, Chiang Mai Province, Doi Suthep, summit, $1600 \mathrm{~m}$.

T. jeekeli Golovatch \& Enghoff, 1993 - Thailand, Chiang Mai Province, Doi Inthanon National Park, Siriphum Waterfall, 1200-1300 m.

T. maculatus Golovatch, 1984 - Vietnam, Lao cai Province, O quy ho, near Sa pa, $1950 \mathrm{~m}$.

T. magicus Golovatch, 1984 - Vietnam, Lao cai Province, O quy ho, near Sa pa, 1950 m. T. mutilatus (Attems, 1953) - Laos, Luang Prabang; Xieng Kuang; Vietnam, Lam Dong Province, Peak Langbiang.

T. nodulipes (Attems, 1953) - Laos, Luang Prabang; Vietnam, Lao cai Province, Mt Fan-Si-Pan. 
T. pallidus Golovatch \& Enghoff, 1993 - Thailand, Chiang Mai Province, Doi Pha Hom Pok, northwest of Fang, 1550-1750 m.

T. perarmatus Hoffman, 1973 - Thailand, Chiang Mai Province, Doi Suthep National Park, east slope, 1100-1275 m; same locality, 1000 m, same locality, 1100 m; same locality, Mahidol Waterfall, 1250 m; same locality, 1400-1500 m; ca 10 miles west of Chiang Mai; Doi Inthanon National Park, Siriphum Waterfall, 1300-1400 m; same locality, Vajirathan Waterfall, 750 m; Doi Chiang Dao, ca 500 m; same locality, limestone cave; Lampang Province, Thoen District, ca $8 \mathrm{~km}$ east of Ban Huai Kaeo, sandy bank of stream, $900 \mathrm{~m}$.

T. perplexus Golovatch \& Enghoff, 1993 - Thailand, Chiang Mai Province, Doi Pha Hom Pok, northwest of Fang, 1550-1750 m.

T. poolpermorum Golovatch \& Enghoff, 1993 - Thailand, Chiang Mai Province, Doi Pha Hom Pok, northwest of Fang, 1550-1750 m.

T. procurvus Golovatch, 1984 - Vietnam, Lao cai Province, O quy ho, pass between Lao cai and Lai chau provinces, 2160 m; same locality, O quy ho, near Sa pa, near stream, $1950 \mathrm{~m}$.

T. prosperus Golovatch \& Enghoff, 1993 - Thailand, Chiang Mai Province, Doi Inthanon National Park, main road, $2200 \mathrm{~m}$; same locality, summit, $2500 \mathrm{~m}$.

T. pulvinipes Golovatch \& Enghoff, 1993 - Thailand, Chaiyaphum Province, Phu Kheio, $16^{\circ} 22^{\prime} \mathrm{N}, 101^{\circ} 34^{\prime} \mathrm{E}$, Tong Kamang Noi, forest, $1000 \mathrm{~m}$.

T. rugosus Golovatch \& Enghoff, 1993 - Thailand, Chiang Mai Province, Chiang Dao, $1800 \mathrm{~m}$.

T. semirugosus Golovatch \& Enghoff, 1993 - Thailand, Tak Province, Mae Sot District, Ban Mussoe.

T. sigma (Attems, 1953) - Vietnam, Lao cai Province, Sa pa.

T. silvestris (Pocock, 1895) - Myanmar, village of Thao (Carin Ghecu), 1200-1400 m.

T. similirugosus Golovatch \& Enghoff, 1993 - Thailand, Chiang Mai Province, Doi Suthep National Park, 1000 m; same locality, 1400-1500 m.

T. sinensis Golovatch, 1995 - China, Yunnan Province, Mengzi County, Pot Hole No. 2 (Ha Fa Tiao Dong).

T. strongylosomoides (Korsós \& Golovatch, 1989) - Vietnam, Vinh phu Province, Tam Dao, north of the village.

T. subcoriaceus Golovatch \& Enghoff, 1993 - Thailand, Chiang Mai Province, Doi Suthep National Park, near stream, 1000 m; same locality, evergreen forest, 1100 m.

T. tamdaoensis Korsós \& Golovatch, 1989 - Vietnam, Vinh phu Province, Tam Dao, north of the village; same locality, subtropical rain forest, ca 800-1200 m.

T. topali Golovatch, 1984 - Vietnam, Ninh binh Province, Cuc Phuong Nature Reserve.

\section{Gonopod structure}

Tylopus is known to be defined, among other characters, by its relatively elaborate gonopod conformation, sometimes perhaps amongst the most complex not only in the tribe 
Sulciferini it belongs to, but also in the Paradoxosomatidae as a whole. Even though a thorough, still fully valid review of gonopod structure is available (Golovatch and Enghoff 1993), we feel tempted to reiterate here the main morphological terms before describing new species and providing some descriptive notes concerning already known congeners.

The gonopod telopodite in Tylopus usually shows a distinct transverse ring, or cingulum, demarcating the postfemoral region which starts at the base of a free, flagelliform solenomere. The solenomere is largely sheathed by a slender and sigmoid solenophore usually bearing a number of outgrowths at its base. The cingulum is only rarely incomplete due to a somewhat reduced sulcus at the base of lobe $\mathbf{l}$, like the one observed in $T$. grandis sp. n. (Figs 5 and 6). Usually lobe $\mathbf{l}$ is simple, but sometimes it can be crowned with a larger (e.g. T. extremus sp. n., Figs 8 and 9, or T. veliger sp. n., Figs 11 and 12) or smaller outgrowth (e.g. T. degerboelae, Figs 20 and 21, or T. nodulipes). In addition to lobe $\mathbf{l}$, the postfemoral region is nearly always supplied with a more or less evident process $\mathbf{h}$ lying mesally of the lobe. However, $\mathbf{h}$ is absent from T. strongylosomoides. All other disto- and/or postfemoral outgrowths, based on their positions, appear to be even more optional. Thus, process $\mathbf{z}$ is mostly discernible, yet occasionally very small (e.g. $T$. parajeekeli, Figs 14 and 15, T. jeekeli, Figs 26 and 27, or T. hoffmani) to fully missing (e.g. T. degerboelae, Figs 20 and 21, T. haplorugosus, Figs 23 and 24, or T. prosperus, Figs 29 and 30 ). Only a few species appear to show particularly complex gonopods. Then not only does the postfemoral region bear a long, spiniform process $\mathbf{z}$, e.g. T. perarmatus (Figs 34 and 35), but also the femorite can be supplied with a small, inconspicuous, lobiform (e.g. T. tamdaoensis) to very long, knife- to spine-shaped, distodorsal outgrowth $\mathbf{m}(T$. extremus sp. n., Figs 8 and 9, or T. perplexus). Besides this, even a few more structures can be added to the postfemoral region, as is observed in T. perplexus. It is the sizes and shapes of these various outgrowths that provide several further important species-specific characters in addition to a good number of peripheral ones (Golovatch and Enghoff 1993).

\section{Description of new species}

\section{Tylopus bispinosus sp. $\mathrm{n}$.}

urn:Isid:zoobank.org:act:D501889C-39AB-427B-A47D-0903412C651C

Figs 1-3

Holotype $\widehat{\delta}$ (CUMZ), Thailand, Tak Province, Umphang District, near Umphang City, ca 490 m, 16 2'20"N, 9852"E, 6.07.2009, leg. S. Panha, J. Sutcharit \& N. Likhitrakarn.

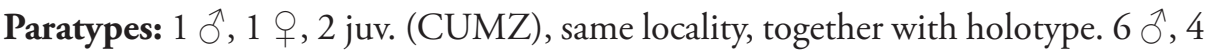
o+ (CUMZ), $3 \widehat{\partial}$ (ZMUC), $3 \widehat{\partial}$ (ZMUM), Tak Province, Umphang District, Doi Hua Mod, 900 m, 16³'14"N, 9849'16"E, 5.06.2009, leg. S. Panha, J. Sutcharit \& N. Likhitrakarn. 6 O , 1 ㅇ (CUMZ), same Province, same District, Cave Ta Ko Bi, ca 530 m, 160' $14 " N$, 9849'14"E, 5.07.2009, leg. S. Panha, J. Sutcharit \& N. Likhitrakarn. 


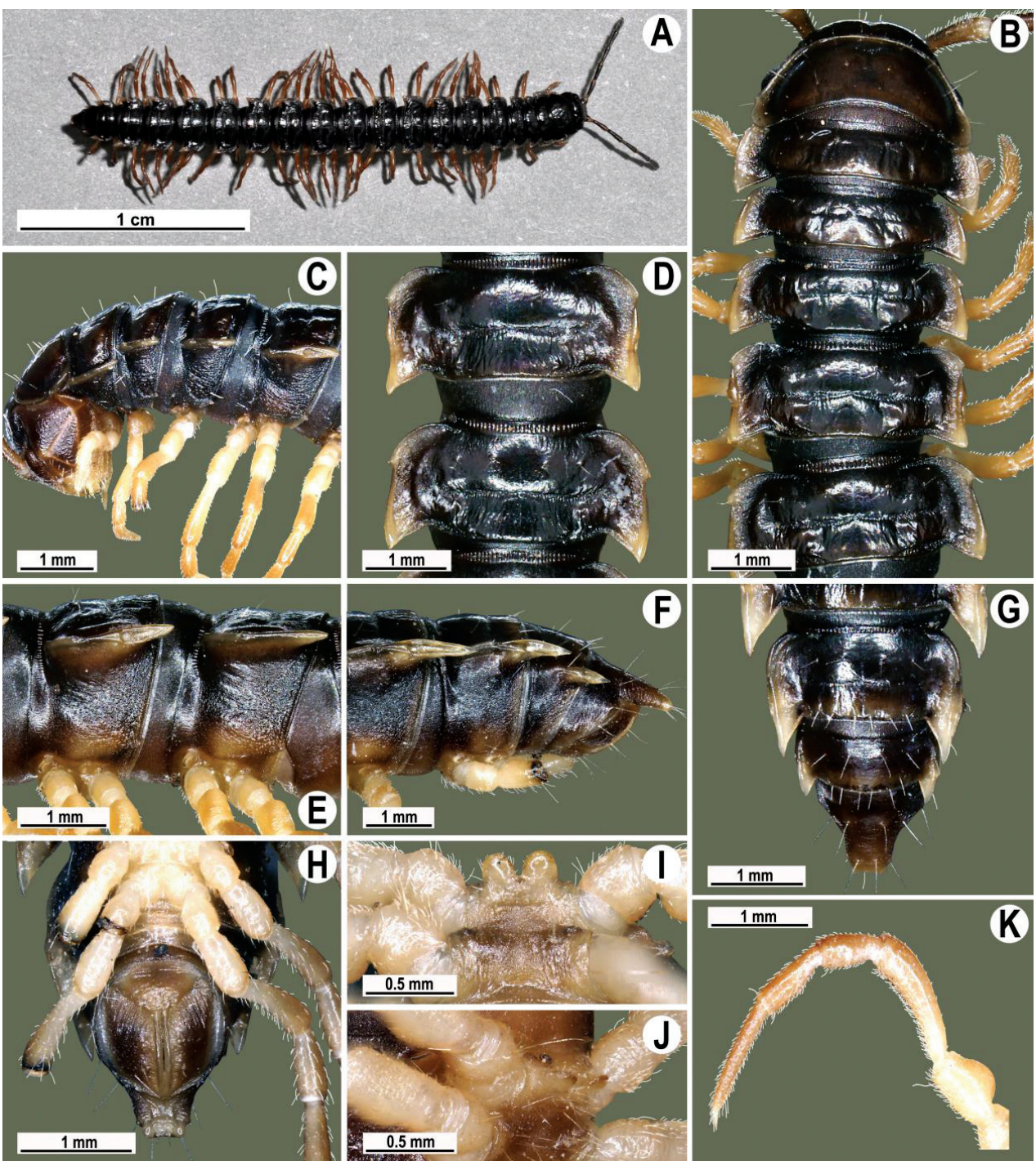

Figure I. Tylopus bispinosus sp. n., ô paratype from near Umphang City (A) and $\widehat{\partial}$ paratype from Doi Hua Mod (B-K). A habitus, live coloration B, C anterior part of body, dorsal and lateral views, respectively. D, E segments 10 and 11, dorsal and lateral views, respectively $\mathbf{F}, \mathbf{G}, \mathbf{H}$ posterior part of body, lateral, dorsal and ventral views, respectively $\mathbf{I}$, J sternal cones between coxae 4, subcaudal and sublateral views, respectively $\mathbf{K}$ midbody leg.

Name: To emphasize the spiniform processes $\mathbf{h}$ and $\mathbf{z}$ of the gonopod.

Diagnosis: Differs from congeners in both processes $\mathbf{h}$ and $\mathbf{z}$ of the gonopod being spiniform.

Description: Length $26 \mathrm{~mm}$ (holotype), 25-29 $\mathrm{mm}\left({ }^{\Uparrow}\right), 33-38 \mathrm{~mm}($ () $)$, width of midbody pro- and metazona 2.0 and $2.9 \mathrm{~mm}$ (holotype), 1.8-2.4 and 3.1-3.2

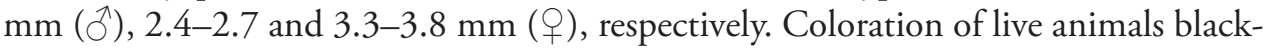




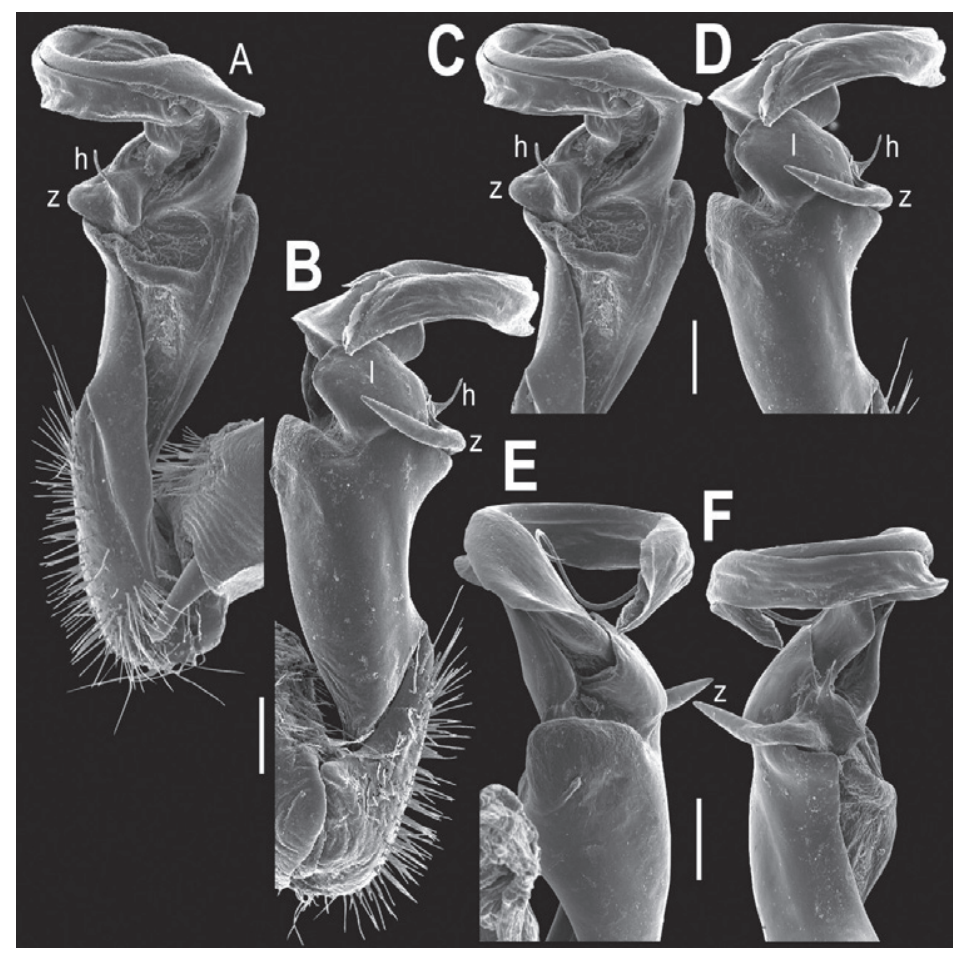

Figure 2. Tylopus bispinosus sp. n., Ø̊ paratype from Doi Hua Mod. A, B right gonopod, mesal and lateral views, respectively $\mathbf{C}-\mathbf{F}$ distal part of right gonopod, mesal, lateral, subcaudal and suboral views, respectively. Scale bar: $0.2 \mathrm{~mm}$.

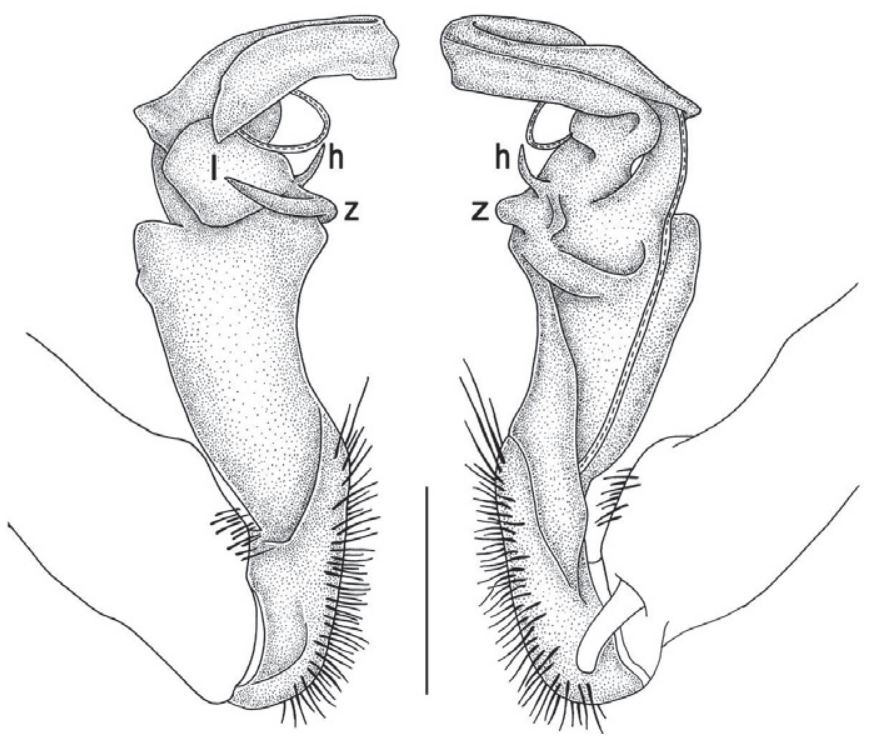

Figure 3.Tylopus bispinosus sp. n., đ̊ paratype from Doi Hua Mod. A, B right gonopod, lateral and mesal views, respectively. Scale bar: $0.5 \mathrm{~mm}$. 
brown (Fig. 1A): calluses of paraterga, venter and legs only slightly lighter, dark brown, but turning light brown in alcohol (Fig. 1A-K).

Clypeolabral region of head very densely, vertigial region sparsely setose. Epicranial suture distinct. Antennae long and slender, reaching behind segment $4\left({ }^{\Uparrow}\right)$ or $3(q)$ dorsally. In width, head $<$ collum $<$ segments $3-4<2<5-16$ ( $\hat{\jmath})$, or head = segment $3<4<$ collum < segments 5-16 (q); thereafter body gradually and gently tapering towards telson (Fig. 1B).

Tegument generally rather smooth and shining, but prozona very finely rugulose, metaterga often rugose (Fig. 1B-G); surface below paraterga finely microgranular (Fig. 1E, F). Collum with three transverse rows of setae: $5+5$ in anterior, $2+2$ in middle, and $4+4$ in posterior row; paraterga evident, rounded, flap-shaped (Fig. 1B, C). Metaterga with two transverse rows of rather long setae: $2+2$ in anterior and $2(3)+2(3)$ in posterior row, the latter often abraded, but then readily traceable as insertion points. Axial line at most barely visible only on metaterga. Paraterga strongly developed (Fig. 1A-G), lying high (at 1/3-1/4 midbody height), only slightly inclined laterally, pointed caudally and acutangular already from segment 2, especially strongly so on caudal segments; calluses very thin on poreless segments, slightly thicker on pore-bearing ones; anterior 1/3 of poreless calluses with two evident (anterior larger, posterior smaller), lateral, setigerous incisions, but with only a single strong one (anterior) on pore-bearing calluses (Fig. 1B-G); paraterga more strongly developed in $\widehat{\sigma}$. Ozopores entirely lateral, lying in an ovoid groove about $1 / 3$ in front of caudal corner, the latter always surpassing rear tergal contour (Fig. 1B-H). Transverse sulcus evident on metaterga 4-18, reaching base of paraterga, evident and rather deep, faintly rugulose at bottom. Stricture between pro- and metazona very clearly ribbed (Fig. 1D). Epiproct tip faintly concave to subtruncate, pre-apical papillae evident (Fig. 1G). Hypoproct roundly subtrapeziform, caudal setae strongly separated (Fig. $1 \mathrm{H})$. Pleurosternal carinae well-developed on segments 2-17 (ठ) or 2-7 (), mostly as low bulges anteriorly and a distinct spine posteriorly (Fig. 1C, E, F).

Sterna moderately setose, without modifications; a deeply notched sternal lobe between $\widehat{\jmath}$ coxae 4 (Fig. 1I, J). Legs long and slender (Fig. 1B, C, H), especially so in $\widehat{\sigma}$ compared to $q$ (1.3-1.5 versus $0.9-1.1$ times as long as midbody height); prefemora distinctly bulged laterally (Fig. $1 \mathrm{~K}$ ), acropodites with particularly dense, nearly adpressed setae, including tarsal brushes.

Gonopods (Figs 2, 3) with lobe $\mathbf{l}$ well-demarcated; spine $\mathbf{h}$ very small; spine $\mathbf{z}$ considerably more prominent.

\section{Tylopus grandis sp. $\mathbf{n}$.}

urn:Isid:zoobank.org:act:148C0F96-F560-437A-92FC-6FA159B96699

Figs 4-6

Holotype $\widehat{\jmath}$ (CUMZ), Thailand, Mae Hong Son Province, Pangmapha District, near Cave Pha Mon, 19.07.2008, leg. S. Panha, J. Sutcharit \& N. Likhitrakarn. 
Paratypes: $1 \hat{\sigma}, 2$ (CUMZ), same locality, together with holotype. $1 \hat{\sigma}$ (CUMZ), same District, Mae Lana crossroads, 19.07.2008, leg. S. Panha, J. Sutcharit \& N. Likhitrakarn.

Name: To emphasize the large size of this species

Diagnosis: Differs from congeners in the large size, coupled with a short spiniform process $\mathbf{h}$, a basally only poorly delimited lobe $\mathbf{l}$, and a small lobiform process $\mathbf{z}$ of the gonopod.

Description: Length $41 \mathrm{~mm}$ (holotype), 40-42 $\mathrm{mm}\left({ }^{\lambda}\right), 38-39 \mathrm{~mm}$ (ㅇ) , width of midbody pro- and metazona 3.0 and $4.5 \mathrm{~mm}$ (holotype), 2.8-3.0 and 4.3-4.5 $\mathrm{mm}\left({ }^{\lambda}\right), 3.6-3.8$ and 4.7-5.0 $\mathrm{mm}($ () $)$, respectively. Coloration in alcohol dark

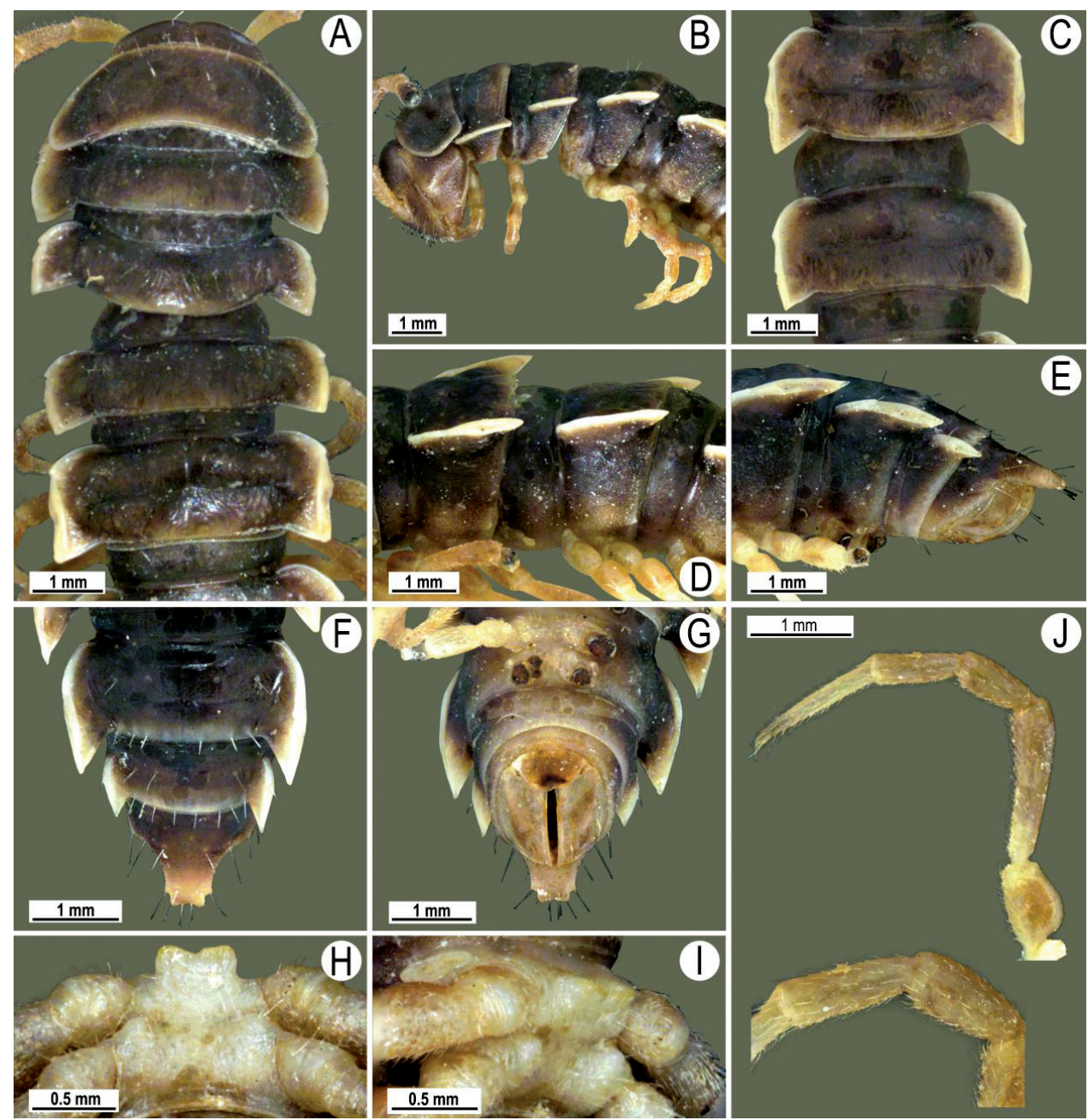

Figure 4. Tylopus grandis sp. n., ô paratype from Mae Lana (A-J). A, B anterior part of body, dorsal and lateral views, respectively $\mathbf{C , D}$ segments 10 and 11 , dorsal and lateral views, respectively $\mathbf{E}, \mathbf{F}, \mathbf{G}$ posterior part of body, lateral, dorsal and ventral views, respectively $\mathbf{H , ~ I ~ s t e r n a l ~ c o n e s ~ b e t w e e n ~ c o x a e ~ 4 , ~ s u b c a u d a l ~}$ and sublateral views, respectively $\mathbf{J}$ midbody leg. 


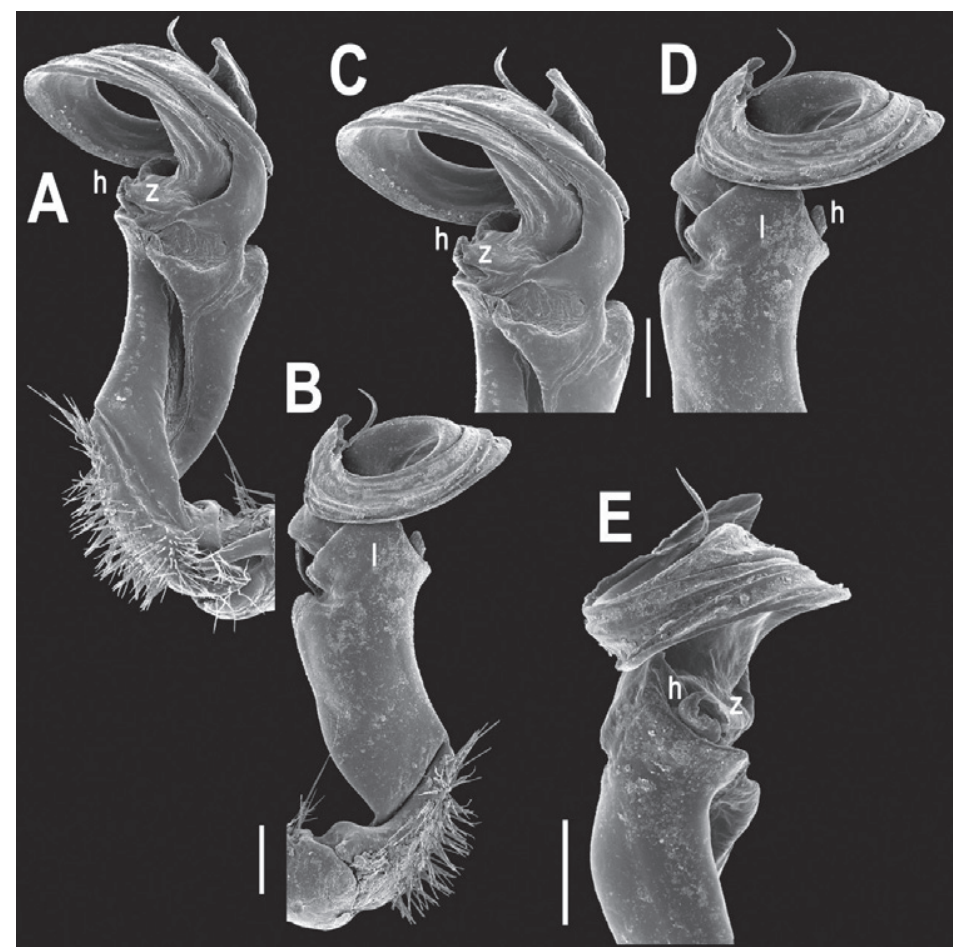

Figure 5. Tylopus grandis sp. n., đ paratype from Mae Lana. A, B right gonopod, mesal and lateral views, respectively C-E distal part of right gonopod, mesal, lateral and suboral views, respectively. Scale bar: $0.2 \mathrm{~mm}$.
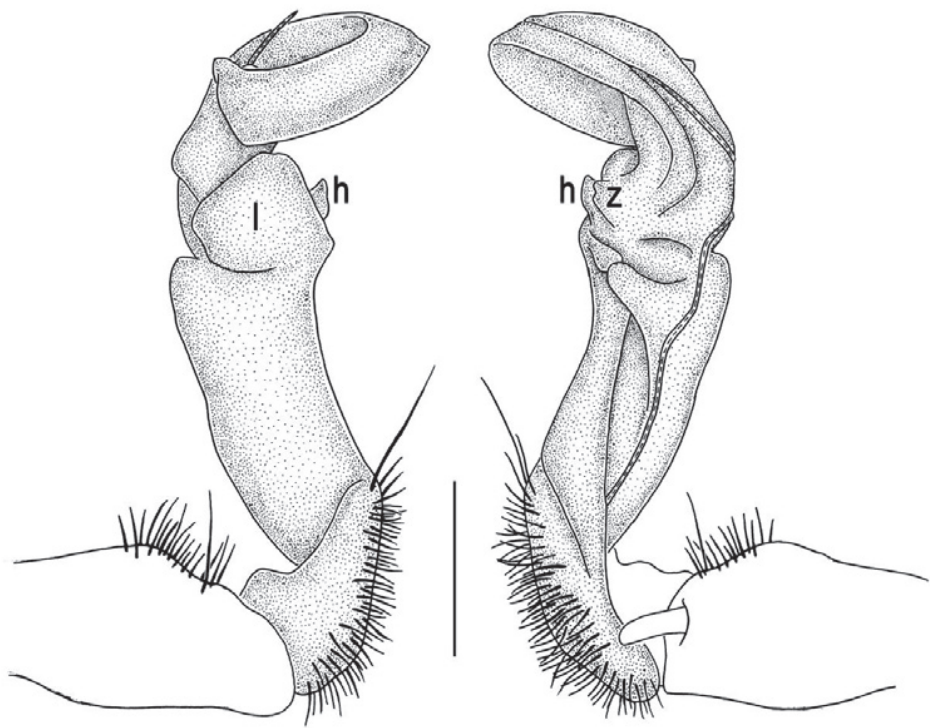

Figure 6. Tylopus grandis sp. n., ô paratype from Mae Lana. A, B right gonopod, lateral and mesal views, respectively. Scale bar: $0.5 \mathrm{~mm}$. 
brown to black-brown (Fig. 4A-G): calluses, venter and antennomeres 1-5 slightly to considerably lighter, brown to light yellow-brown (Fig. 1A-G), antennomeres 6 and 7 dark brown.

All characters as in T. bispinosus sp. n., except as follows.

Antennae short and slender (Fig. 4B), reaching behind segment $3\left({ }^{\lambda}\right)$ or $2($ ( $)$ dorsally. In width, head $<$ collum $=$ segments $3-4<2=5-16(\widehat{O})$, or head $<$ segments $3-4<$ collum $<$ segment $2<5-16$ (O); thereafter body gradually and gently tapering towards telson (Fig. 4A-F).

Tegument generally rather smooth and either dull (only in places modestly shining) or shining (Fig. 4A-G). Paraterga strongly developed (Fig. 4A-G), lying high (at 1/4-1/5 midbody height), subhorizontal to slightly upturned laterally (Fig. 4A-F). Transverse sulcus either absent or poorly developed, then not reaching bases of paraterga 4, always evident and reaching bases of paraterga 5-18, rather faintly rugulose at bottom. Stricture between pro- and metazona rather faintly beaded to striolate(Fig. 4A-C). Epiproct tip evidently emarginate, pre-apical papillae very distinct (Fig. 4F, G). Hypoproct semi-circular, caudal setae strongly separated (Fig. 4G). Pleurosternal carinae visible on segments 2-15(16) (ठ) or segments 2-6 (Q), mostly as low bulges anteriorly and a more or less distinct denticle posteriorly (Fig. 4B, D).

Sterna moderately setose, without modifications; a slightly notched sternal lobe between $\widehat{O}$ coxae 4 (Fig. 4H, I). Legs long and slender (Fig. 1B, C, H), especially so in $\widehat{\sigma}$ compared to + (1.7-1.8 versus $1.5-1.6$ times as long as midbody height); $\delta$ prefemora distinctly bulged laterally (Fig. 4J), acropodites with particularly dense, nearly adpressed setae, but tarsal brushes missing.

Gonopods (Figs 5, 6) with lobe $\mathbf{l}$ poorly demarcated at base; spine $\mathbf{h}$ very small; process $\mathbf{z}$ not spiniform, but like a short lobe.

\section{Tylopus extremus sp. $\mathbf{n}$.}

urn:Isid:zoobank.org:act:188F2E10-CAC7-406A-B176-6818DF526D0B Figs 7-9

Holotype $\delta$ (CUMZ), Thailand, Chiang Mai Province, Fang District, Doi Phahom Pok National Park, 6.07.2009, leg. A. Pansook.

Paratypes: $1 \hat{\partial}, 1$ ㅇ (CUMZ), $1 \hat{\partial}$ (ZMUC), $1 \hat{\delta}$ (ZMUM), same locality, together with holotype.

Name: To emphasize the extremely long spines $\mathbf{h}$ and $\mathbf{m}$ of the gonopod.

Diagnosis: Differs from congeners in process $\mathbf{h}$ being subflagelliform while process $\mathbf{m}$ extremely long and prominent.

Description: Length ca $30 \mathrm{~mm}$ (holotype), $27-30 \mathrm{~mm}$ ( $\left.{ }^{\lambda}\right), 32.5 \mathrm{~mm}$ (ㅇ), width of midbody pro- and metazona 2.0 and $2.9 \mathrm{~mm}$ (holotype), $1.9-2.4$ and $2.8-3.3 \mathrm{~mm}$ (ふ), 2.5 and $3.0 \mathrm{~mm}($ ( $)$, respectively. Coloration of live animals, as well as of alcohol material black-brown (Fig. 7A-G): calluses of paraterga and antennae only slightly 
lighter, light brown to brown, venter and legs contrastingly light, yellow (Fig. 7A-G), tip of antennae pallid.

All characters as in T. bispinosus sp. n., except as follows.

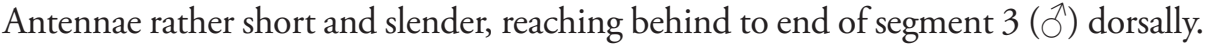
Collum with paraterga like rudimentary flaps, especially poorly developed in 9 . In width, head $<$ collum $=$ segments $3-4<2<5-16\left({ }^{\Uparrow}\right)$ (Fig. 7B), or head $<$ collum $<$ segment $3<$ 2 and $4<5-16(+$ ( ); thereafter body gradually and gently tapering towards telson.

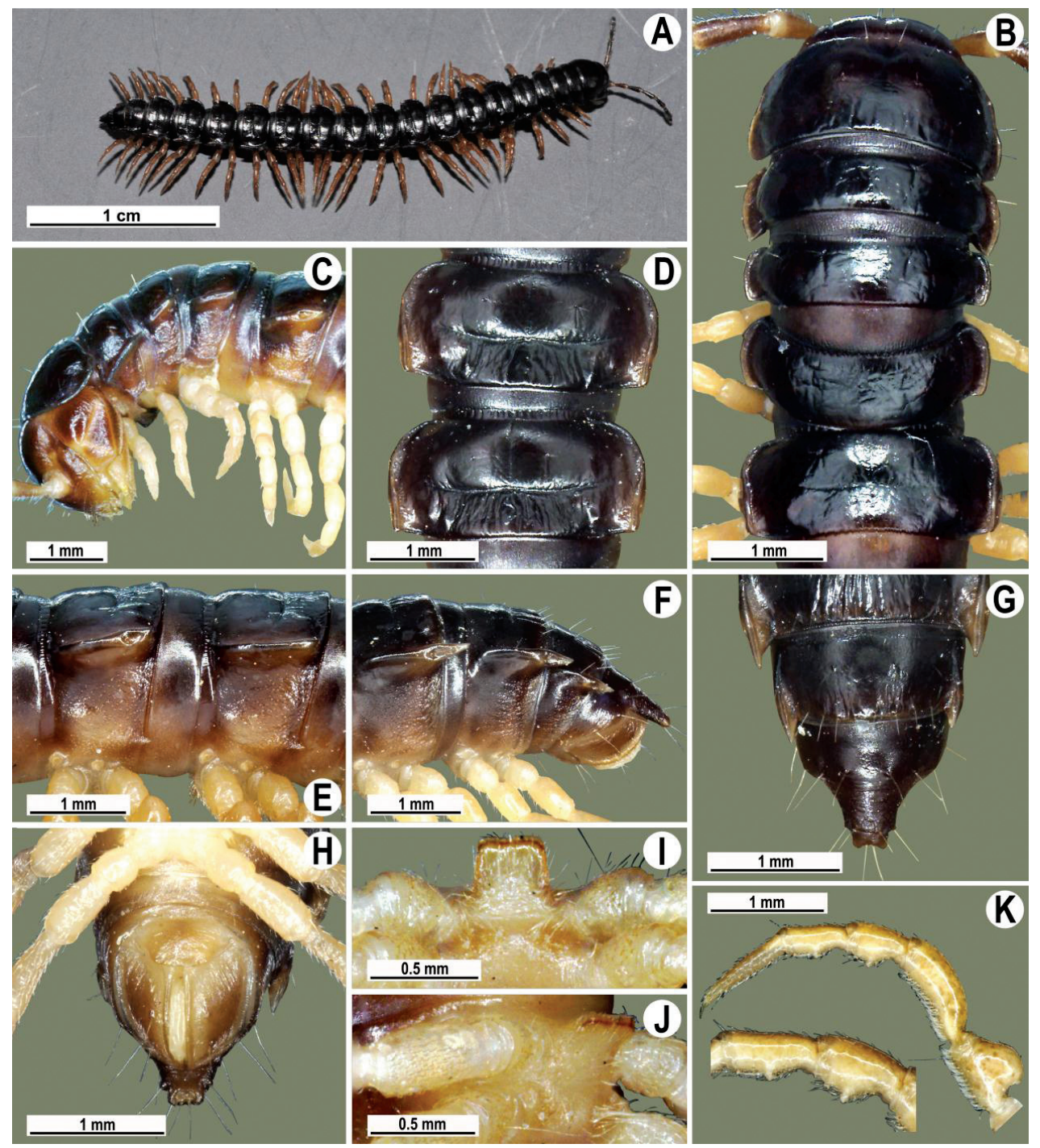

Figure 7. Tylopus extremus sp. n., ô paratype (A-K). A habitus, live coloration B, $\mathbf{C}$ anterior part of body, dorsal and lateral views, respectively $\mathbf{D}, \mathbf{E}$ segments 10 and 11, dorsal and lateral views, respectively $\mathbf{F}, \mathbf{G}, \mathbf{H}$ posterior part of body, lateral, dorsal and ventral views, respectively $\mathbf{I}, \mathbf{J}$ sternal cones between coxae 4, subcaudal and sublateral views, respectively $\mathbf{K}$ midbody leg. 


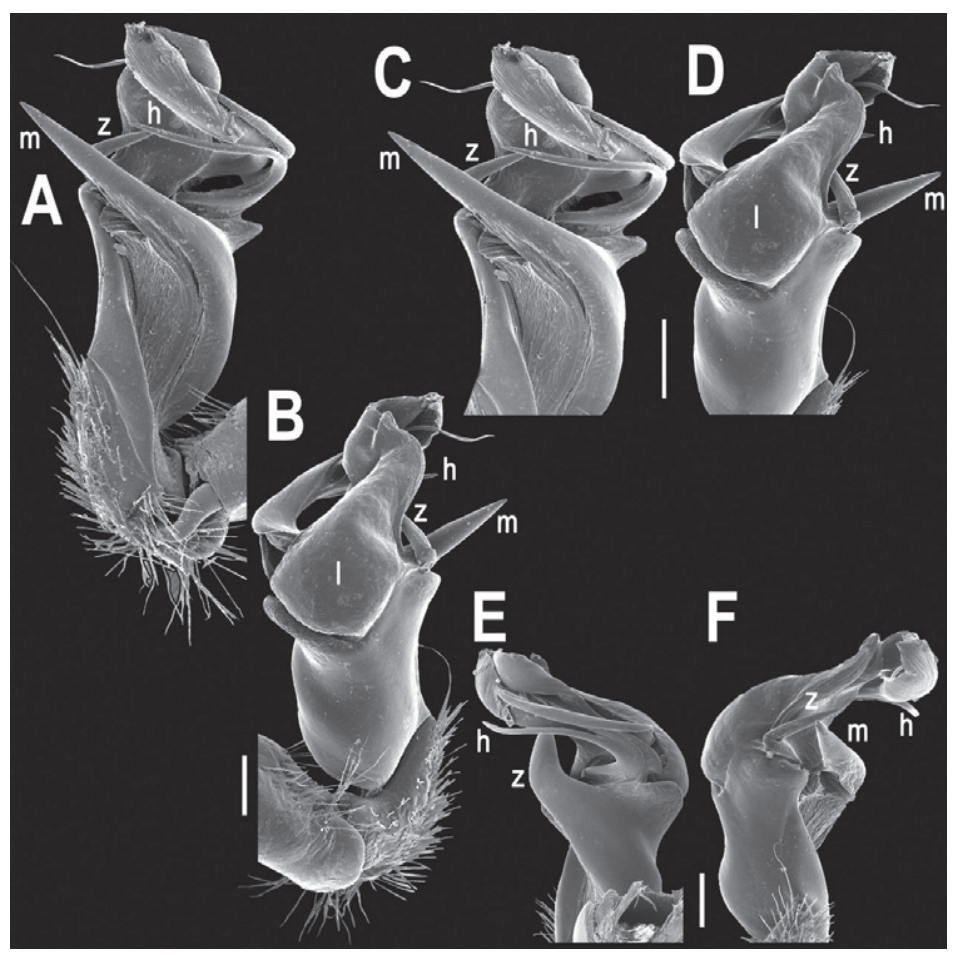

Figure 8. Tylopus extremus sp. n., ổ paratype. A, B right gonopod, mesal and lateral views, respectively C-F distal part of right gonopod, mesal, lateral, subcaudal and suboral views, respectively. Scale bar: $0.2 \mathrm{~mm}$.
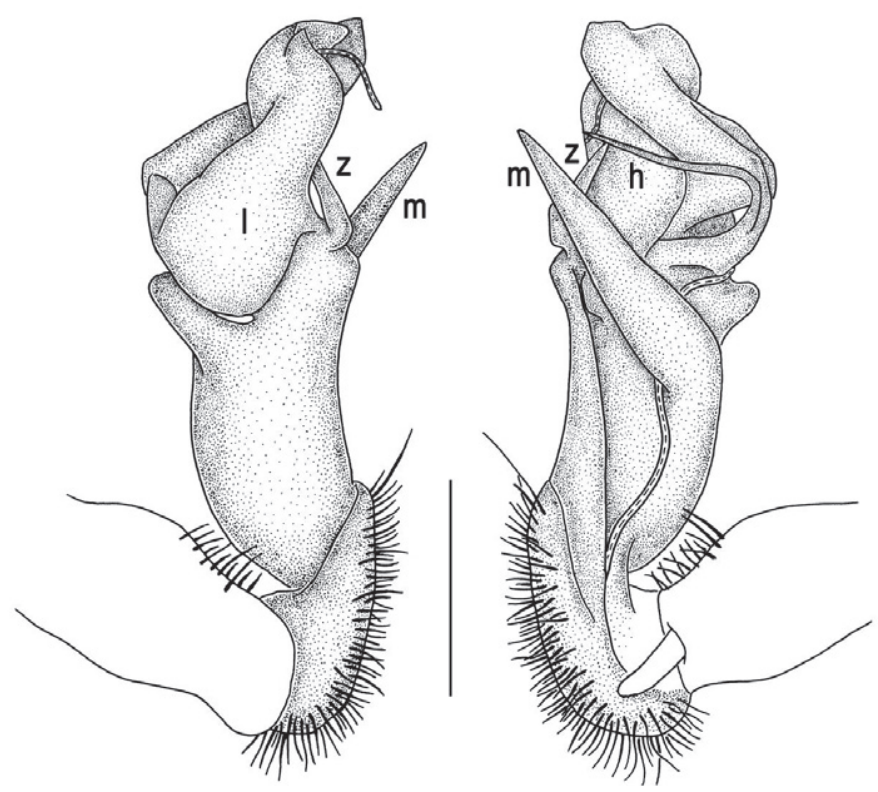

Figure 9. Tylopus extremus sp. n., ô paratype. A, B right gonopod, lateral and mesal views, respectively. Scale bar: $0.5 \mathrm{~mm}$. 
Metaterga with two transverse rows of rather long setae: $2+2$ in anterior and $2(3)+2(3)$ in posterior row, the latter often abraded, but then readily traceable as insertion points on low longitudinal ridges or tubercles (Fig. 7B-G). Axial line thin, visible on both halves of metaterga. Paraterga strongly developed (Fig. 7A-G), lying rather low (at 1/2-1/3 midbody height), slightly inclined laterally, pointed caudally and acutangular already from segment 2, especially strongly so on caudal segments, very clearly surpassing rear contour only on segments $16-19$; anterior $1 / 3$ of poreless calluses with two barely visible, lateral, setigerous incisions, but with only a single, likewise poorly developed incision anteriorly on pore-bearing calluses (Fig. 7B-F); paraterga slightly less strongly developed in $q$. Transverse sulcus evident on metaterga 5-18, reaching bases of paraterga, evident and rather deep, faintly rugulose at bottom. Stricture between pro- and metazona weakly striolate (Fig. 7B-G). Epiproct emarginate at tip, pre-apical papillae evident (Fig. 7G). Hypoproct subtrapeziform, caudal setae widely separated (Fig. $7 \mathrm{H}$ ). Pleurosternal carinae as compete ridges with a caudal tooth on segments 2-4 ( $\widehat{\sigma})$ or 2 and $3($ ( ) , like separated anterior bulges and increasingly poorly developed caudal denticles until segment 16 (Fig. 7C, E, F).

Sterna moderately setose, without modifications; an entire, linguiform, sternal lobe between $\widehat{\sigma}$ coxae 4 (Fig. 7I, J). Legs long, in $\widehat{\jmath}$ very distinctly incrassate, 1.7-2.0 or ca 1.3 times as long as midbody height in $\hat{\sigma}$ and $q$, respectively (Fig. $7 \mathrm{~B}, \mathrm{C}, \mathrm{H}$ ), $\widehat{\sigma}$ prefemora very distinctly bulged laterally and clothed with dense and adpressed pilosity ventrally (Fig. $7 \mathrm{~K}$ ), acropodites also with similarly dense and ventrally adpressed pilosity, including tarsal brushes. All $\delta$ postfemora and tibiae except for a few posteriormost ones with a small, but evident adenostyle (= tubercle) at midway on ventral side (Fig. 7K).

Gonopods (Figs 8, 9) with lobe 1 well-demarcated, but unusually prominent, high and elongated; spine $\mathbf{h}$ long, extremely slender and subflagelliform; spine $\mathbf{z}$ rather short and simple; spine $\mathbf{m}$ very prominent, straight and long.

\section{Tylopus veliger sp. $\mathrm{n}$.}

urn:lsid:zoobank.org:act:54694D7D-8C76-4705-B81F-0949DFE0D787

Figs 10-12

Holotype $\widehat{\jmath}$ (CUMZ), Thailand, Nan Province, Pua District, Ton Tong Waterfall, ca $1130 \mathrm{~m}, 19^{\circ} 10^{\prime} 52^{\prime \prime N}, 101^{\circ} 5^{\prime} 45^{\prime} \mathrm{E}, 10.10 .2009$, leg. S. Panha, J. Sutcharit \& N. Likhitrakarn.

Name: To emphasize the velum-shaped end of gonopod lobe $\mathbf{l}$.

Diagnosis: Differs from congeners except T. perplexus Golovatch \& Enghoff, 1993 in the distal part of gonopod lobe $\mathbf{1}$ being velum-shaped and supplied with two denticles, from $T$. perplexus in the gonopod lacking spines $\mathbf{m}$ and $\mathbf{q}$, as well as in a much shorter and knife-shaped spine $\mathbf{z}$, and a rudimentary spine $\mathbf{h}$.

Description: Length ca $28 \mathrm{~mm}$, width of midbody pro- and metazona 2.0 and $2.6 \mathrm{~mm}$, respectively. Coloration of live animal and alcohol material rather uniformly 


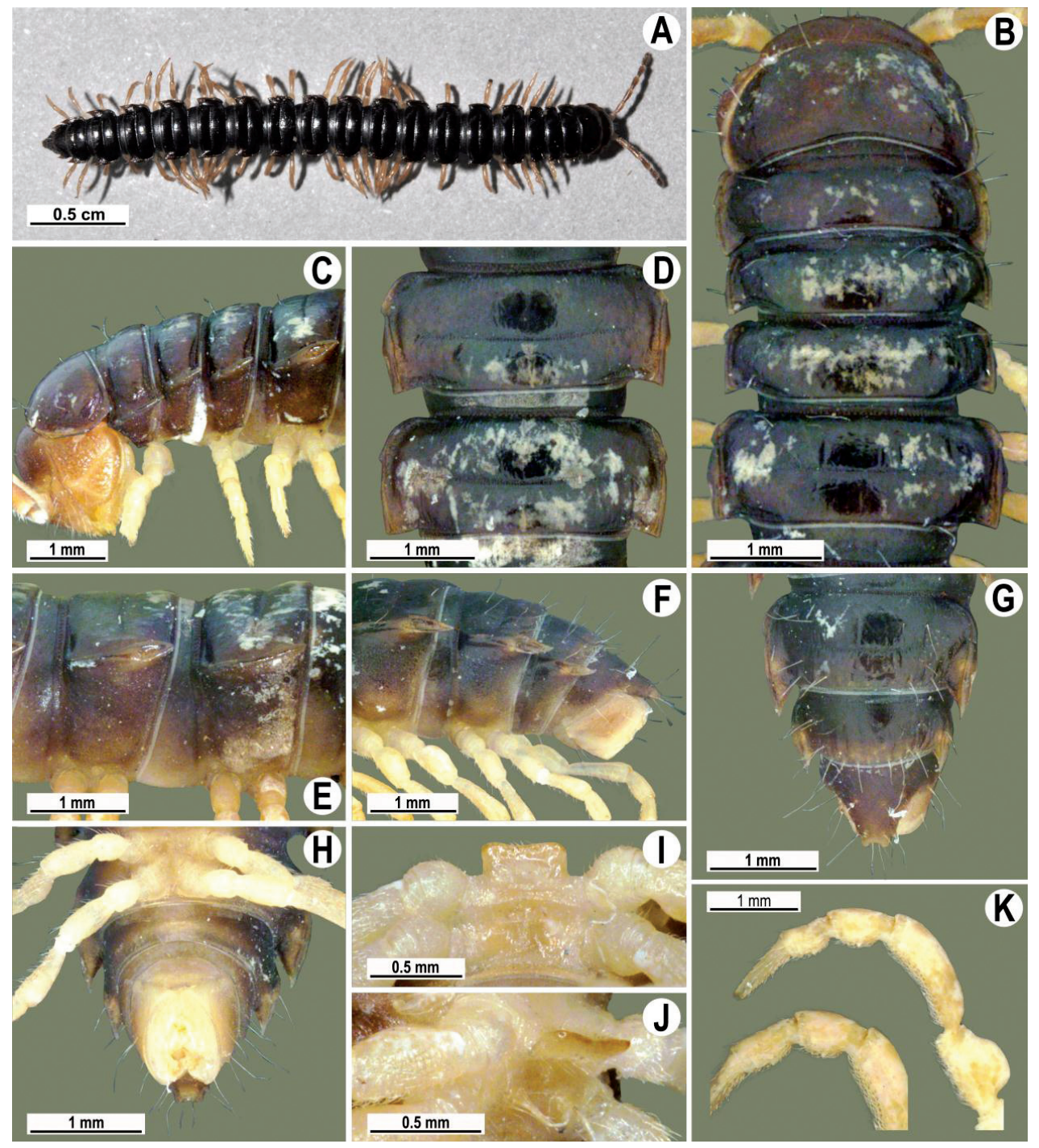

Figure 10. Tylopus veliger sp. n., đo holotype (A-K). A habitus, live coloration B, C anterior part of body, dorsal and lateral views, respectively $\mathbf{D}, \mathbf{E}$ segments 10 and 11, dorsal and lateral views, respectively $\mathbf{F}, \mathbf{G}, \mathbf{H}$ posterior part of body, lateral, dorsal and ventral views, respectively $\mathbf{I}, \mathbf{J}$ sternal cones between coxae 4, subcaudal and sublateral views, respectively $\mathbf{K}$ midbody leg.

dark brown to blackish (Fig. 1A); calluses of paraterga only slightly flavous, brown; antennomeres 1-6 and genae light brown; venter and legs contrastingly yellowish to light brown (Fig. 10A-G).

All characters as in T. bispinosus sp. n., except as follows.

Clypeolabral region of head very densely setose, but vertigial region bare. Antennae short and barely reaching behind segment 2 dorsally. In width, head = segments 3 and $4<$ collum $<$ segment $2<5-16$; thereafter body gradually and gently tapering 


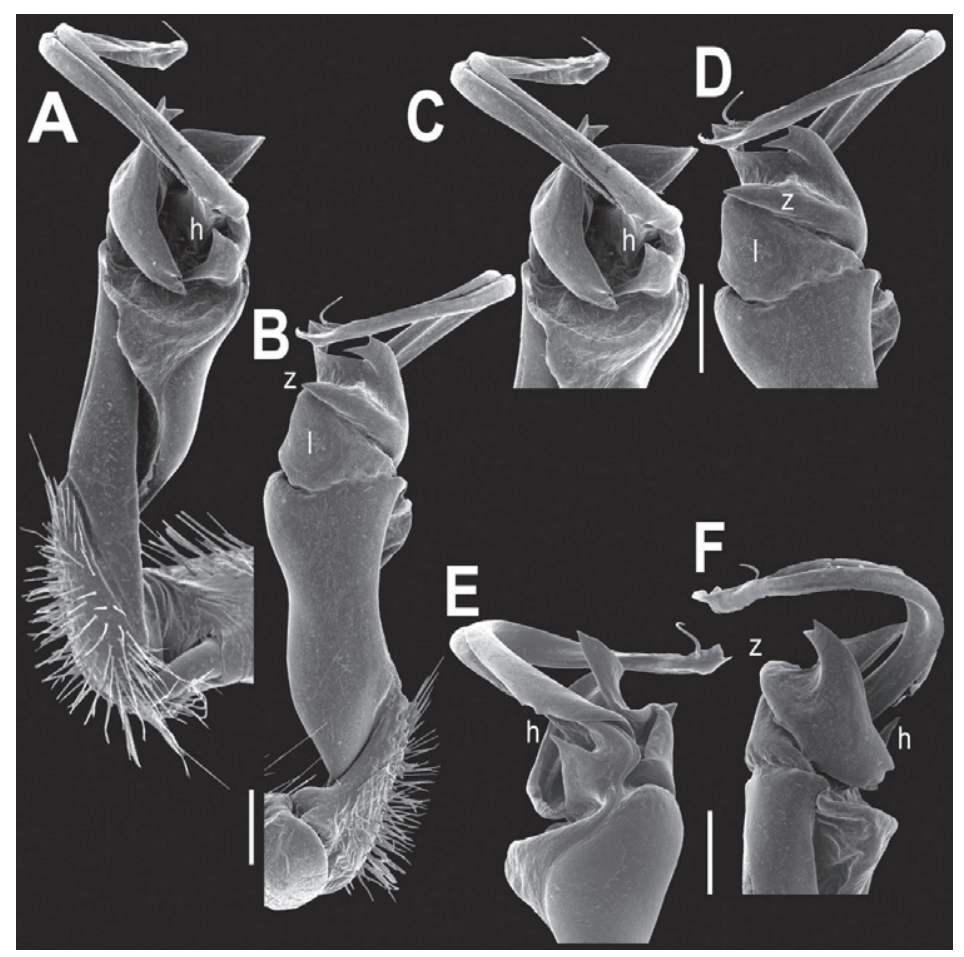

Figure II. Tylopus veliger sp. n., ô holotype. A, B right gonopod, mesal and lateral views, respectively C-F distal part of right gonopod, mesal, lateral, subcaudal and suboral views, respectively. Scale bar: $0.2 \mathrm{~mm}$.
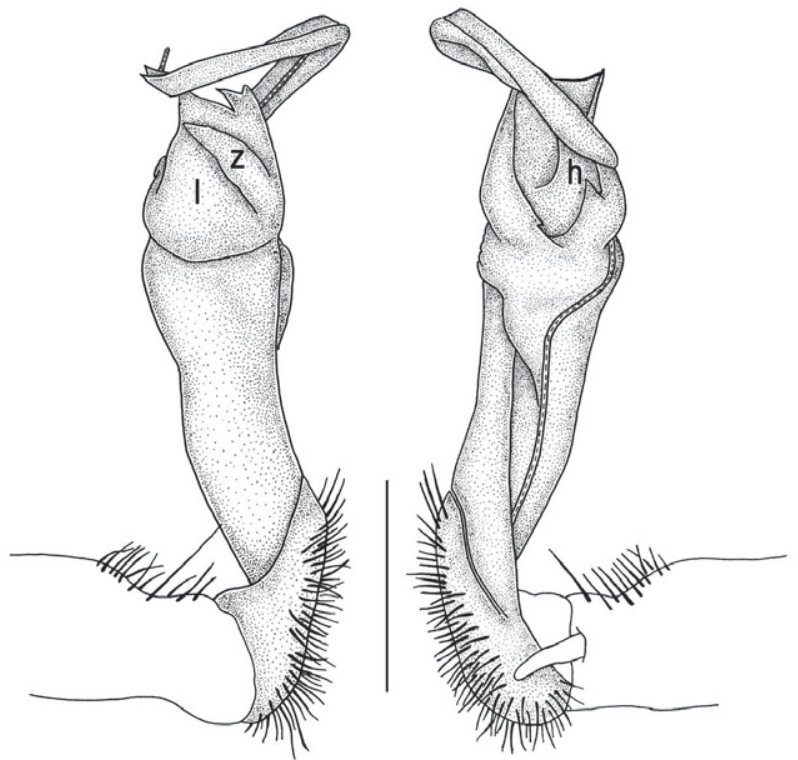

Figure 12. Tylopus veliger sp. n., ô holotype. A, B right gonopod, lateral and mesal views, respectively. Scale bar: $0.5 \mathrm{~mm}$. 
towards telson (Fig. 10A-G). Collum with small, narrowly delimited, rounded, stripshaped paraterga (Fig 10B, C).

Metaterga with two transverse rows of long setae: $2+2$ in anterior and 2(3)+2(3) in posterior row, the latter often abraded, but then readily traceable as insertion points. Axial line thin, in places incomplete, but readily visible on both halves of metaterga. Paraterga strongly developed (Fig. 10A-G), lying relatively low (at $1 / 2-1 / 3$ midbody height), evidently inclined ventrolaterally, pointed caudally and acutangular already from segment 2, especially strongly so and surpassing rear tergal contour on segments 16-19; calluses slightly thinner on poreless segments than on pore-bearing ones; poreless calluses with two lateral setigerous incisions, but with only a single, more evident one (anterior) on pore-bearing calluses (Fig. 10B-G). Transverse sulcus evident on metaterga 5-18, reaching bases of paraterga, evident and rather deep, finely, densely and clearly ribbed at bottom. Stricture between pro- and metazona very clearly ribbed (Fig. 10B-G). Epiproct tip clearly emarginate, pre-apical papillae evident (Fig. 10F-H). Hypoproct semi-circular, caudal setae strongly separated (Fig. 10H). Pleurosternal carinae as complete ridges on segments $2-4$, thereafter broken into an anterior bulge and a caudal tooth, both growing increasingly reduced until segment 16 (Fig. 10C, E, F).

Sterna rather densely setose, without modifications except for a subquadrate, setose, sternal lobe between coxae 4 (Fig. 10I, J). Legs relatively short, ca 1.2-1.3 times as long as midbody height, evidently incrassate (Fig. 10C, F, K); prefemora distinctly bulged laterally and clothed with mostly adpressed setae ventrally (Fig. 10K), acropodites likewise with very dense, mostly adpressed setae ventrally; postfemora and tibiae slightly bulged ventrally; tarsal brushes missing.

Gonopods (Figs 11,12) with lobe 1 well-demarcated, high and prominent, apically with a pointed fan-shaped structure (= velum) and two denticles; spine $\mathbf{h}$ very small, dentiform; spine $\mathbf{z}$ prominent, knife-shaped, lying above $\mathbf{l}$ on lateral side.

\section{Tylopus parajeekeli sp. $\mathbf{n}$.}

urn:Isid:zoobank.org:act:703DB743-0898-4B3A-8D37-A4DD31FE7CD1

Figs $13-15$

Holotype $\delta$ (CUMZ), Thailand, Chiang Mai Province, Chom Thong District, Doi Inthanon National Park, summit, 2520 m, 18 34'29"N, 98²8'48"E, 12.10.2009, leg. S. Panha, J. Sutcharit \& N. Likhitrakarn.

Paratype: $1 \delta$ (CUMZ), same locality, together with holotype.

Name: To emphasize the close resemblance to T. jeekeli Golovatch \& Enghoff, 1993.

Diagnosis: Very similar to $T$. jeekeli, especially as regards its gonopod conformation, but differs in the paraterga lying much lower (at ca $1 / 3$ versus $1 / 4-1 / 5$ midbody height), in the caudal corners of the paraterga protruding behind the rear tergal contour already from segment 16 (versus segment 2), and also in gonopod spine $\mathbf{z}$ being much smaller and placed closer to the base of spine $\mathbf{h}$. 


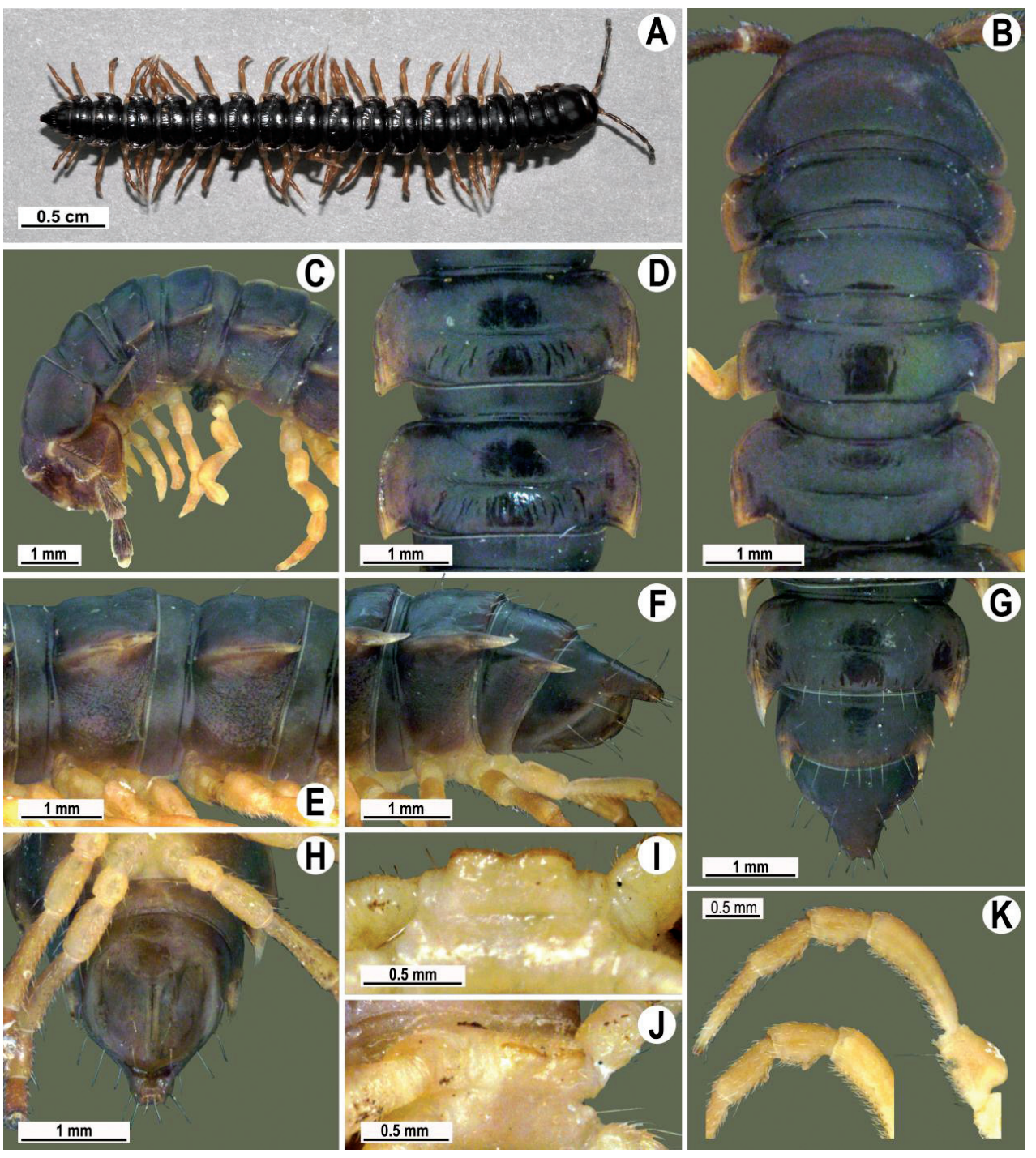

Figure 13. Tylopus parajeekeli sp. n., ô holotype (A) and ô paratype (B-K). A habitus, live coloration $\mathbf{B}, \mathbf{C}$ anterior part of body, dorsal and lateral views, respectively $\mathbf{D}, \mathbf{E}$ segments 10 and 11, dorsal and lateral views, respectively $\mathbf{F}, \mathbf{G}, \mathbf{H}$ posterior part of body, lateral, dorsal and ventral views, respectively $\mathbf{I}$, J sternal cones between coxae 4, subcaudal and sublateral views, respectively $\mathbf{K}$ midbody leg.

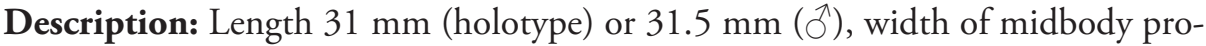
and metazona 2.4 and $3.2 \mathrm{~mm}$ (holotype) or 2.3 and $3.4 \mathrm{~mm}(\widehat{\widehat{O}})$, respectively. Coloration of live animals and alcohol material uniformly blackish-brown (Fig. 13A-G); calluses of paraterga a little lighter, brown; antennomeres 1-5 light brown to yellowish, legs and venter light brown to grey-yellowish (Fig. 13A-G).

All characters as in T. bispinosus sp. n., except as follows. 


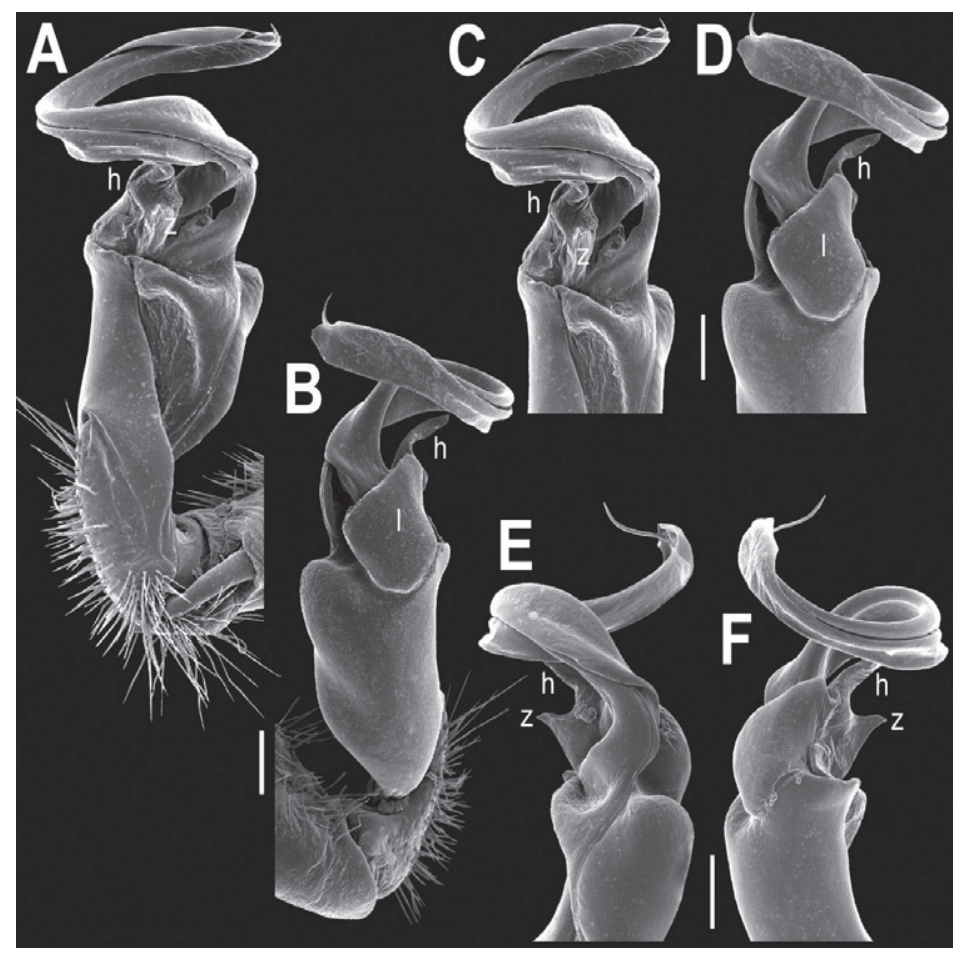

Figure 14. Tylopus parajeekeli sp. n., ô paratype. A, B right gonopod, mesal and lateral views, respectively C-F distal part of right gonopod, submesal, sublateral, subcaudal and suboral views, respectively. Scale bar: $0.2 \mathrm{~mm}$.
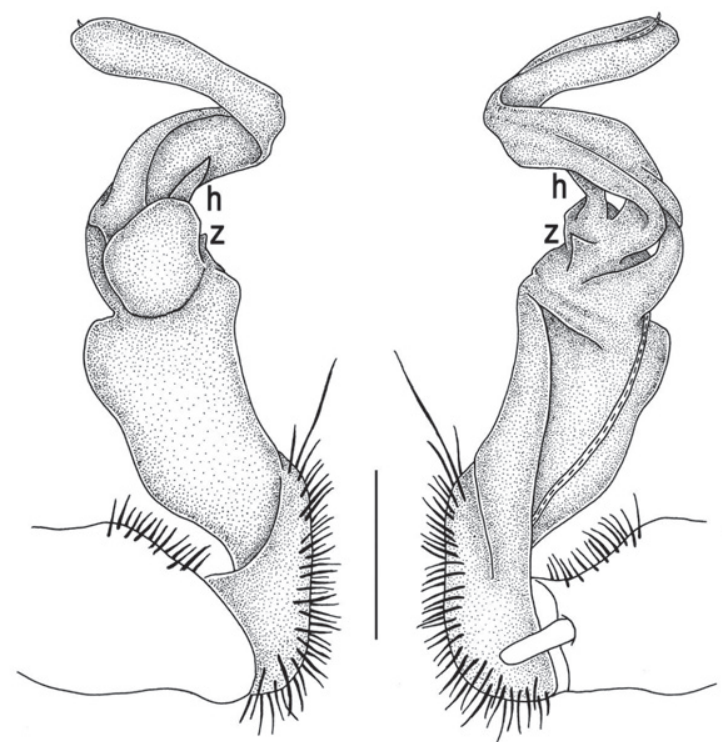

Figure 15. Tylopus parajeekeli sp. n., ô paratype. A, B right gonopod, lateral and mesal views, respectively. Scale bar: $0.5 \mathrm{~mm}$. 
Antennae rather short and slender, reaching behind segment 3 dorsally. In width, head $=$ segment $3<$ collum $<$ segments 2 and $4<5-16$; thereafter body gradually and gently tapering towards telson (Fig. 1B).

Paraterga on collum like large rounded flaps (Fig. 13B, C). Following paraterga lying at about $1 / 3$ midbody height, evidently declined ventrolaterally, subhorizontal only on a few posteriormost segments, mostly pointed caudally, subrectangular until segment 15 , thereafter increasingly well protruding behind rear tergal contour (Fig. 13A-G). Metaterga with $2(3)+2(3)$ and $3-5+3-5$ long setae arranged in two transverse rows. Axial line present on both halves of metaterga. Transverse sulcus present on segments 5-18, very finely beaded at bottom (Fig. 13B, F, G). Stricture between pro- and metazona finely striolate (Fig. 13B, D). Epiproct tip broad and emarginate (Fig. 13G, H). Hypoproct semi-circular, both caudal setae widely separated (Fig. $13 \mathrm{H}$ ). Pleurosternal carinae as complete ridges on segments 2-4, thereafter retained until segment 17 mostly as a small caudal tooth (Fig. 13C-F).

A low, only slightly divided, setose lobe between coxae 4 (Fig. 13I, J). Legs relatively short, ca 1.6-1.7 times as long as midbody height (Fig. 13K). Femora evidently bulged laterally (Fig. 13K); all postgonopodal legs except two last pairs with an evident adenostyle in parabasal $1 / 3$ of each postfemur and tibia; tarsal brushes missing; all telopoditomeres except tarsi with dense adpressed pilosity (Fig. 13K).

Gonopods (Figs 14, 15) with lobe $\mathbf{l}$ well-demarcated; spine $\mathbf{h}$ small, but elongate, not bifid; spine $\mathbf{z}$ very small, dentiform, placed at base of spine $\mathbf{h}$.

\section{New faunistic records}

The following seven species have been illustrated in additional detail to confirm their identities, as well as to provide further information concerning both their variation and distribution.

\section{Tylopus allorugosus Golovatch \& Enghoff, 1993}

Figs $16-18$

Tylopus allorugosus Golovatch \& Enghoff, 1993: 100.

Tylopus allorugosus: Enghoff, 2005: 98.

Material: $2 \widehat{\jmath}$ (CUMZ), Thailand, Chiang Mai Province, Chom Thong District, Doi Inthanon National Park, Siriphum Waterfall, ca 1320 m, 18³2'49"N, 98 30'57"E, 13.10.2009, leg. S. Panha, J. Sutcharit \& N. Likhitrakarn; 2 (CUMZ), same locality, main road, $10 \mathrm{~km}$ before summit, ca $1700 \mathrm{~m}, 18^{\circ} 31^{\prime} 15^{\prime \prime N}, 98^{\circ} 30^{\prime} 1{ }^{\prime \prime E}, 13.10 .2009$, leg. S. Panha, J. Sutcharit \& N. Likhitrakarn.

Remarks. This strictly topotypic material fully agrees with the original description (Golovatch and Enghoff 1993), showing no evident variation in peripheral and gonopod structure (Figs 16-18). 


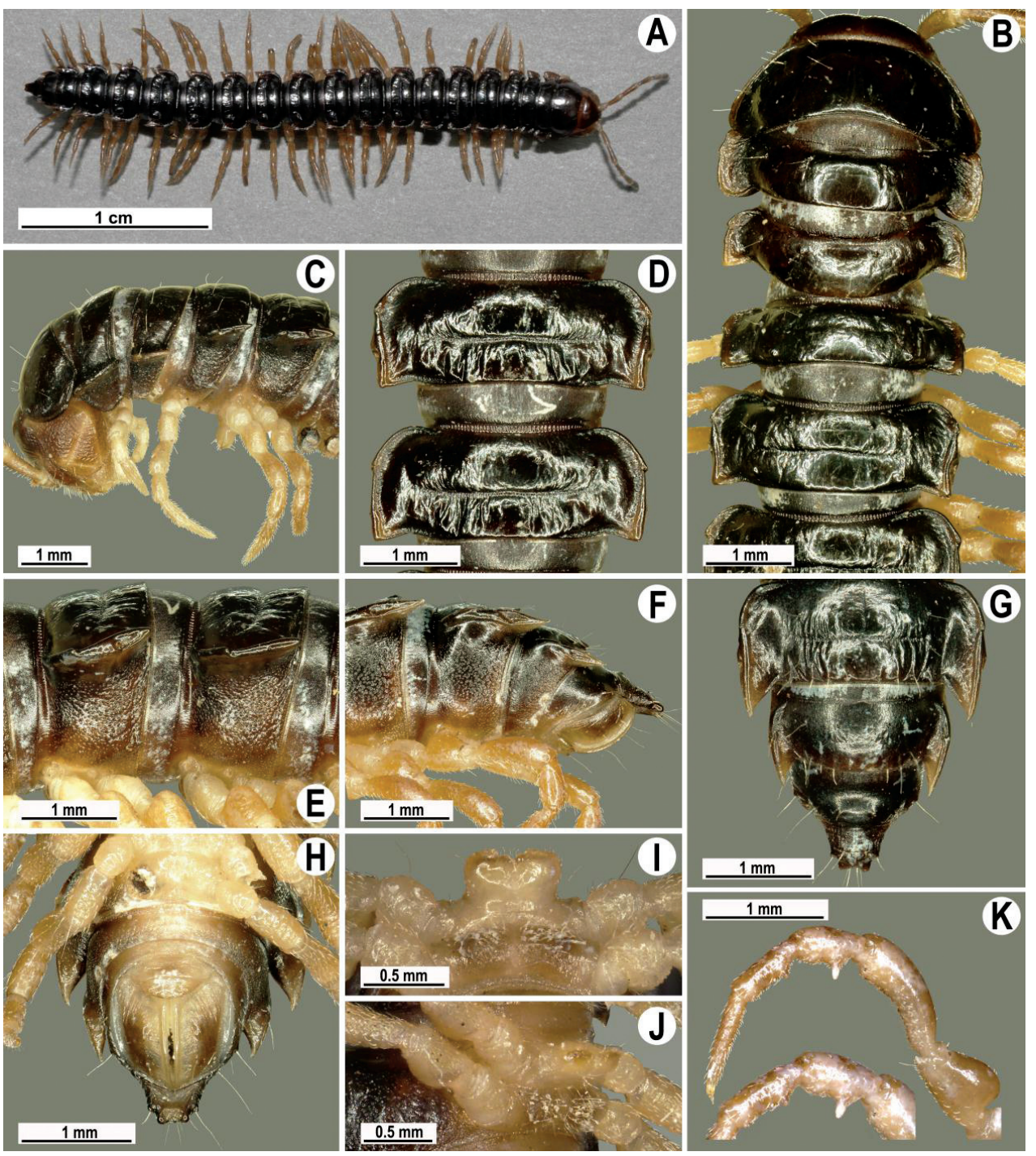

Figure 16. Tylopus allorugosus Golovatch \& Enghoff, 1993, ô from $10 \mathrm{~km}$ before Doi Inthanon summit (A-K). A habitus, live coloration B, C anterior part of body, dorsal and lateral views, respectively D, E segments 10 and 11, dorsal and lateral views, respectively $\mathbf{F}, \mathbf{G}, \mathbf{H}$ posterior part of body, lateral, dorsal and ventral views, respectively $\mathbf{I}, \mathbf{J}$ sternal cones between coxae 4, subcaudal and sublateral views, respectively $\mathbf{K}$ midbody leg.

\section{Tylopus degerboelae Golovatch \& Enghoff, 1993}

Figs 19-21

Tylopus degerboelae Golovatch \& Enghoff, 1993: 111.

Tylopus degerboelae: Enghoff, 2005: 99. 


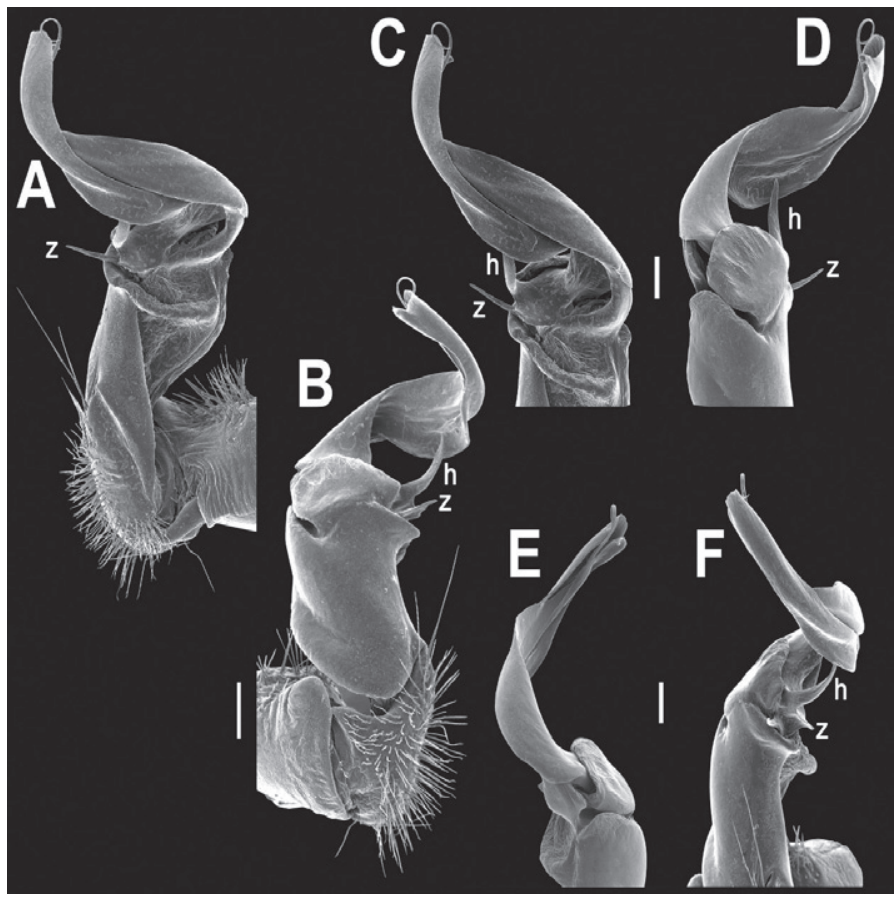

Figure 17. Tylopus allorugosus Golovatch \& Enghoff, 1993, § from $10 \mathrm{~km}$ before Doi Inthanon summit. A, B right gonopod, mesal and lateral views, respectively $\mathbf{C}-\mathbf{F}$ distal part of right gonopod, submesal, sublateral, subcaudal and suboral views, respectively. Scale bar: $0.2 \mathrm{~mm}$.
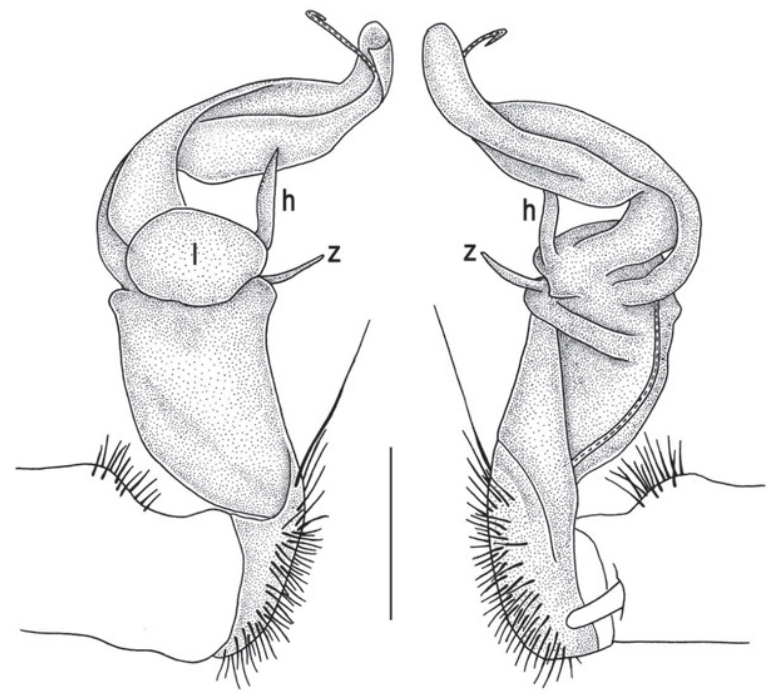

Figure 18. Tylopus allorugosus Golovatch \& Enghoff, 1993, § from $10 \mathrm{~km}$ before Doi Inthanon summit. A, B right gonopod, lateral and mesal views, respectively. Scale bar: $0.5 \mathrm{~mm}$. 
Material: $3 \curvearrowright$ (CUMZ), Thailand, Chiang Mai Province, Mueang Chiang Mai District, Doi Suthep National Park, ca 1300 m, 1848'9"N, 9854'11"E, 20.04.2009, leg. S. Panha, J. Sutcharit \& N. Likhitrakarn; 4 O , 3 +, 2 juv. (CUMZ), same Province, WiangKaen District, Doi Phatang, 6.07.2009, leg. S. Panha \& J. Sutcharit.

Remarks. This partly topotypic material fully agrees with the original description (Golovatch and Enghoff 1993), showing only slight variation in general coloration (ranging from pale castaneous to piceous), in $\widehat{\partial}$ prefemora often being considerably bulged laterally, and in the tip of lobe $\mathbf{l}$ of the gonopod often devoid of apical denticles (Figs 19-21).

\section{Tylopus haplorugosus Golovatch \& Enghoff, 1993}

Figs 22-24

Tylopus haplorugosus Golovatch \& Enghoff, 1993: 99.

Tylopus haplorugosus: Enghoff, 2005: 99.

Material: $1 \hat{\partial}$ (CUMZ), Thailand, Chiang Mai Province, Chom Thong District, Doi Inthanon National Park, main road, $10 \mathrm{~km}$ before summit, ca $1700 \mathrm{~m}, 18^{\circ} 31^{\prime} 15^{\prime \prime N}$, 98³0'1"E, 13.10.2009, leg. S. Panha, J. Sutcharit \& N. Likhitrakarn.

Remarks. This strictly topotypic material fully agrees with the original description (Golovatch and Enghoff 1993), showing no evident variation in peripheral and gonopod structure (Figs 22-24).

\section{Tylopus jeekeli Golovatch \& Enghoff, 1993}

Figs 25-27

Tylopus jeekeli Golovatch \& Enghoff, 1993: 108.

Tylopus jeekeli: Enghoff, 2005: 99.

Material: 4 o, 7 †, 1 juv. (CUMZ), Thailand, Chiang Mai Province, Mueang Chiang Mai District, Doi Suthep National Park, ca 1300 m, 1848'9"N, 98 54'11"E, 22.10.2009, leg. S. Panha, J. Sutcharit \& N. Likhitrakarn.

Remarks. This represents a second record of this species, the type locality being Doi Inthanon National Park in the same province. Our material almost fully agrees with the original description (Golovatch and Enghoff 1993), showing slight variation only in spine $\mathbf{h}$ of the gonopod being non-bifid, but simple and entire (Figs 25-27). 


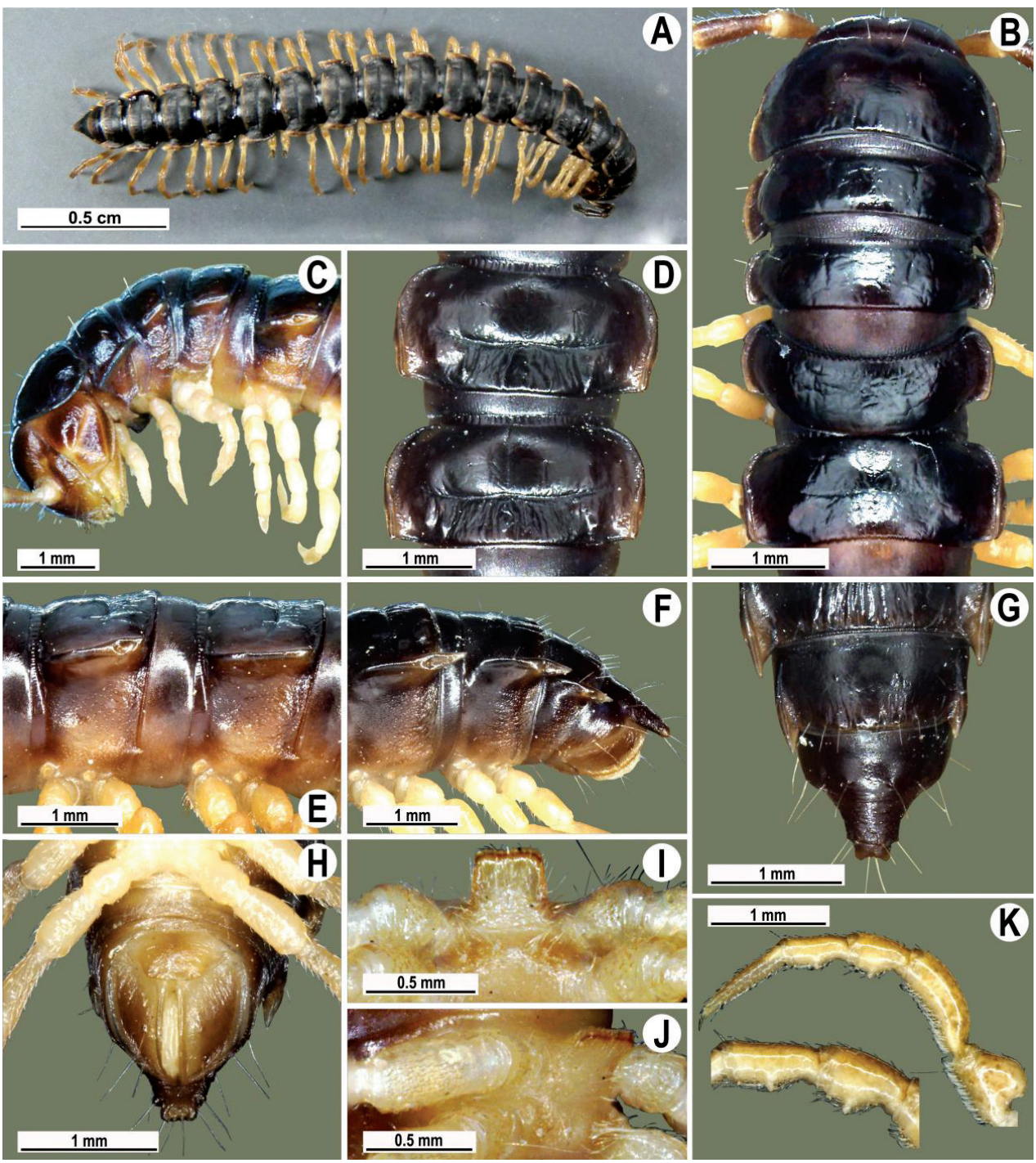

Figure 19. Tylopus degerboelae Golovatch \& Enghoff, 1993, đ̂ from Doi Suthep National Park (A-K). A habitus, live coloration $\mathbf{B}, \mathbf{C}$ anterior part of body, dorsal and lateral views, respectively $\mathbf{D}, \mathbf{E}$ segments 10 and 11, dorsal and lateral views, respectively $\mathbf{F}, \mathbf{G}, \mathbf{H}$ posterior part of body, lateral, dorsal and ventral views, respectively I, J sternal cones between coxae 4, subcaudal and sublateral views, respectively $\mathbf{K}$ midbody leg.

Tylopus prosperus Golovatch \& Enghoff, 1993

Figs $28-30$

Tylopus prosperus Golovatch \& Enghoff, 1993: 93.

Tylopus prosperus: Enghoff, 2005: 99. 


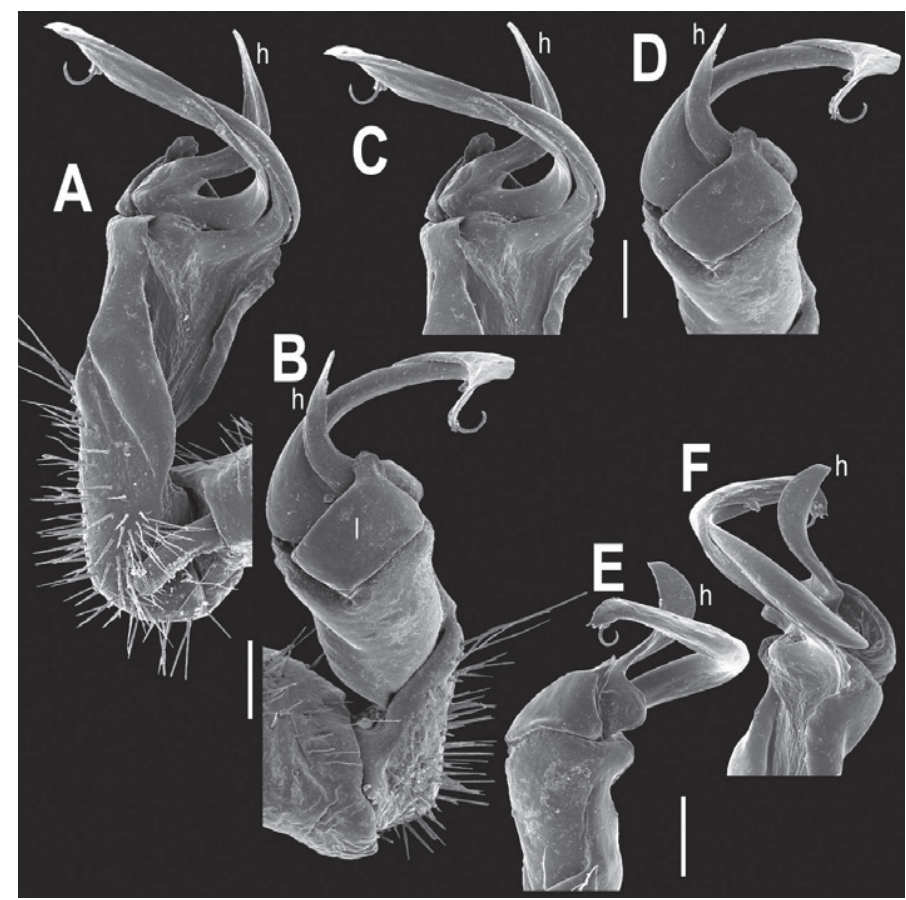

Figure 20. Tylopus degerboelae Golovatch \& Enghoff, 1993, ô from Doi Suthep National Park. A, B right gonopod, mesal and lateral views, respectively $\mathbf{C}-\mathbf{F}$ distal part of right gonopod, mesal, lateral, subcaudal and suboral views, respectively. Scale bar: $0.2 \mathrm{~mm}$.
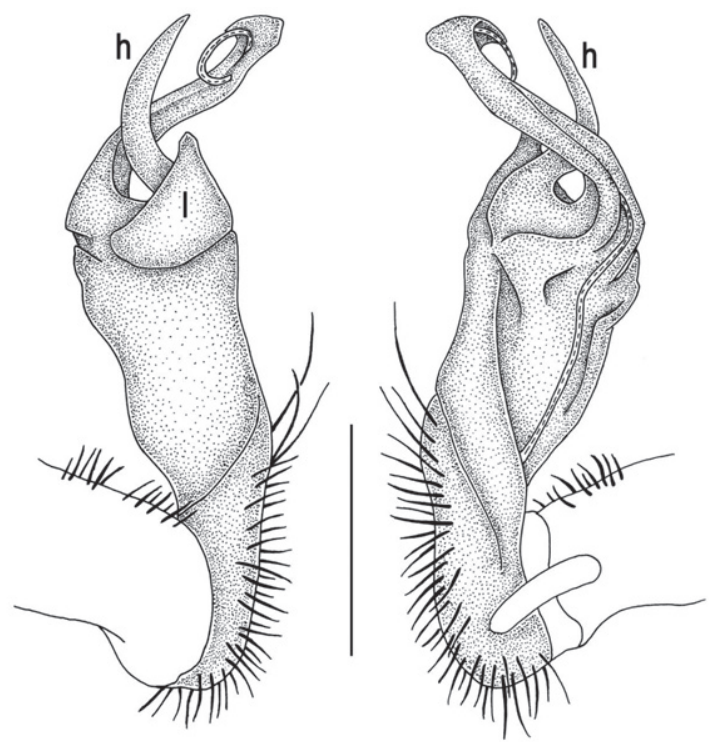

Figure 21. Tylopus degerboelae Golovatch \& Enghoff, 1993, đ̊ from Doi Suthep National Park. A, B right gonopod, lateral and mesal views, respectively. Scale bar: $0.5 \mathrm{~mm}$. 


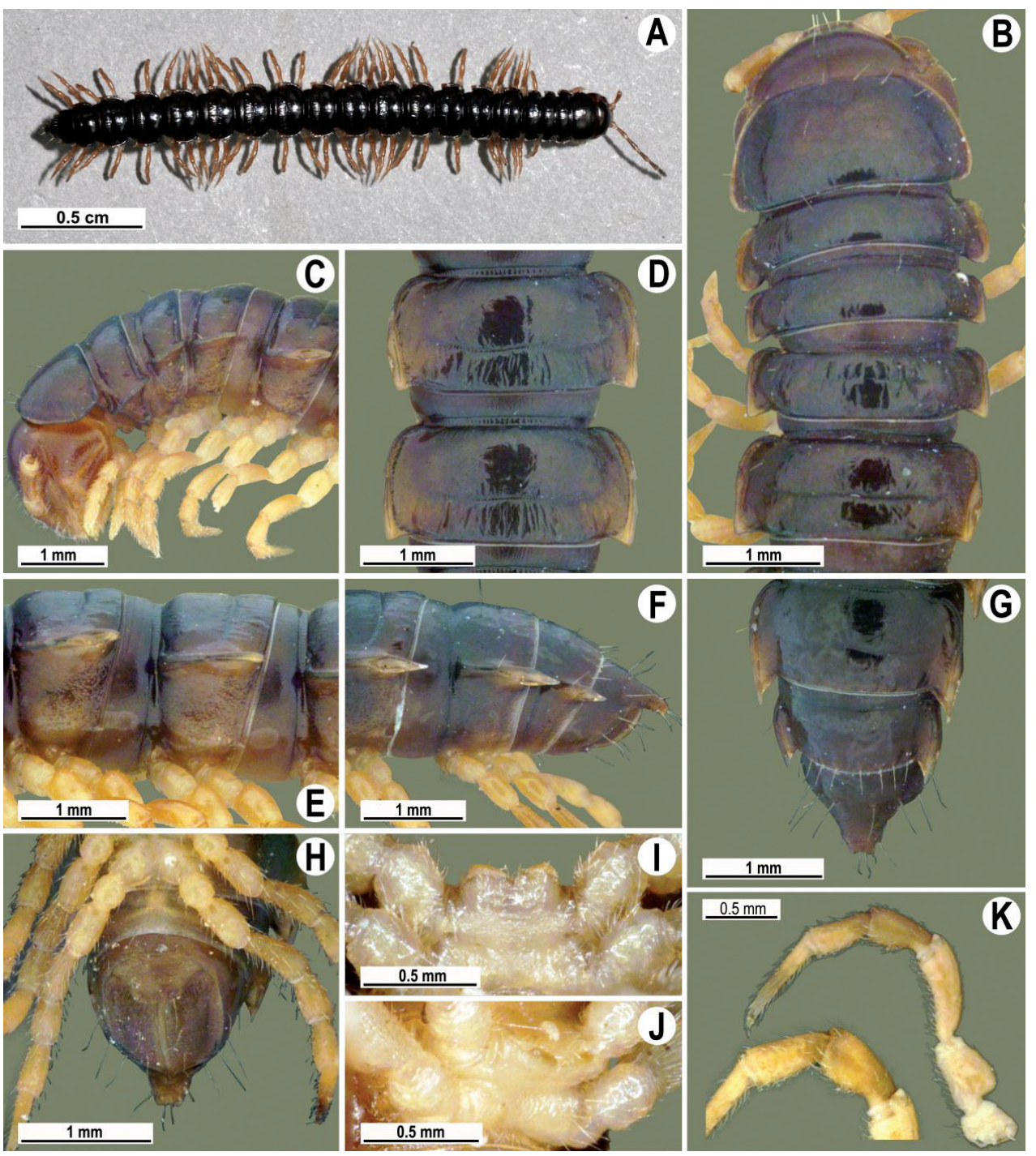

Figure 22. Tylopus haplorugosus Golovatch \& Enghoff, 1993, ô (A-K). A habitus, live coloration B, C anterior part of body, dorsal and lateral views, respectively $\mathbf{D}, \mathbf{E}$ segments 10 and 11, dorsal and lateral views, respectively $\mathbf{F}, \mathbf{G}, \mathbf{H}$ posterior part of body, lateral, dorsal and ventral views, respectively $\mathbf{I}, \mathbf{J}$ sternal cones between coxae 4, subcaudal and sublateral views, respectively $\mathbf{K}$ midbody leg.

Material: $2 \widehat{\jmath}$ (CUMZ), Thailand, Chiang Mai Province, Chom Thong District, Doi Inthanon National Park, summit, 2520 m, 18³4'29"N, 98²8'48"E, 12.10.2009, leg. S. Panha, J. Sutcharit \& N. Likhitrakarn.

Remarks. This strictly topotypic material fully agrees with the original description (Golovatch and Enghoff 1993), showing no evident variation in peripheral and gonopod structure (Figs 28-30). 


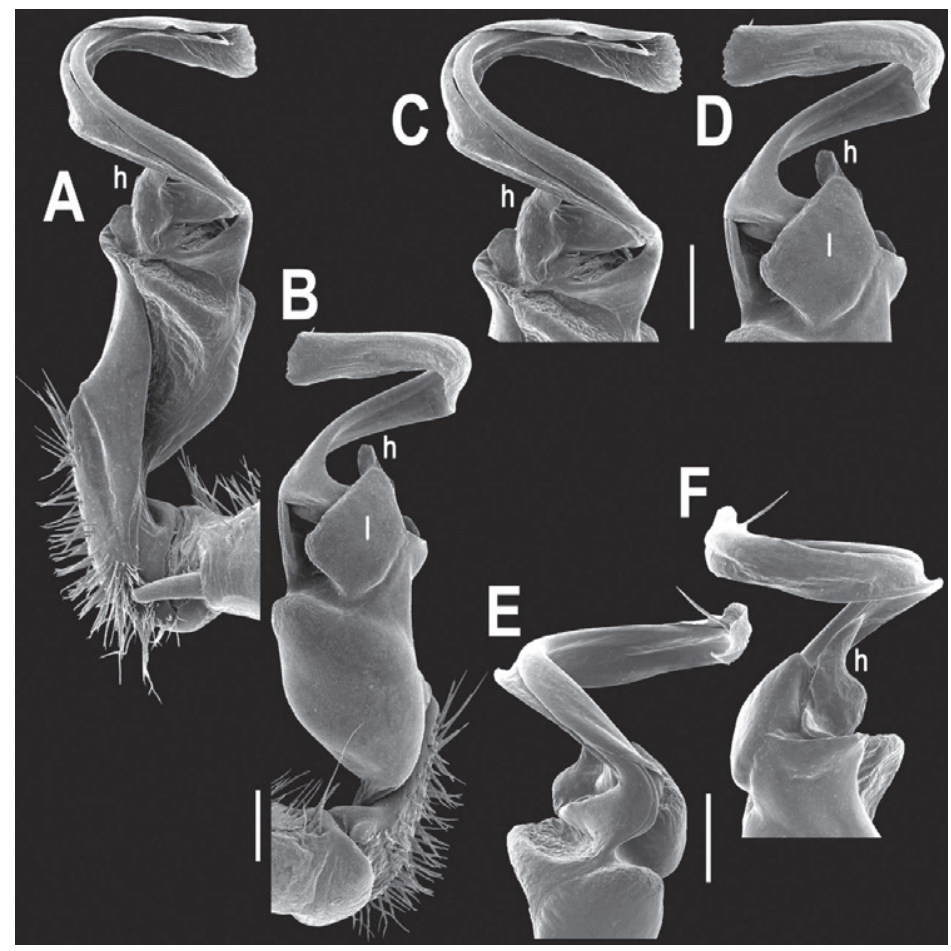

Figure 23. Tylopus haplorugosus Golovatch \& Enghoff, 1993, O̊. A, B right gonopod, mesal and lateral views, respectively $\mathbf{C}-\mathbf{F}$ distal part of right gonopod, mesal, lateral, subcaudal and suboral views, respectively. Scale bar: $0.2 \mathrm{~mm}$.
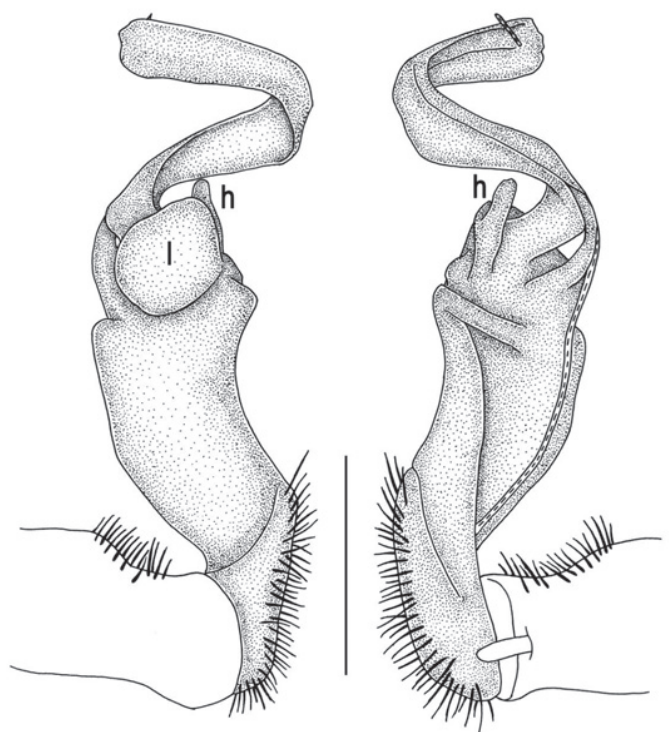

Figure 24. Tylopus haplorugosus Golovatch \& Enghoff, 1993, ô. A, B right gonopod, lateral and mesal views, respectively. Scale bar: $0.5 \mathrm{~mm}$. 


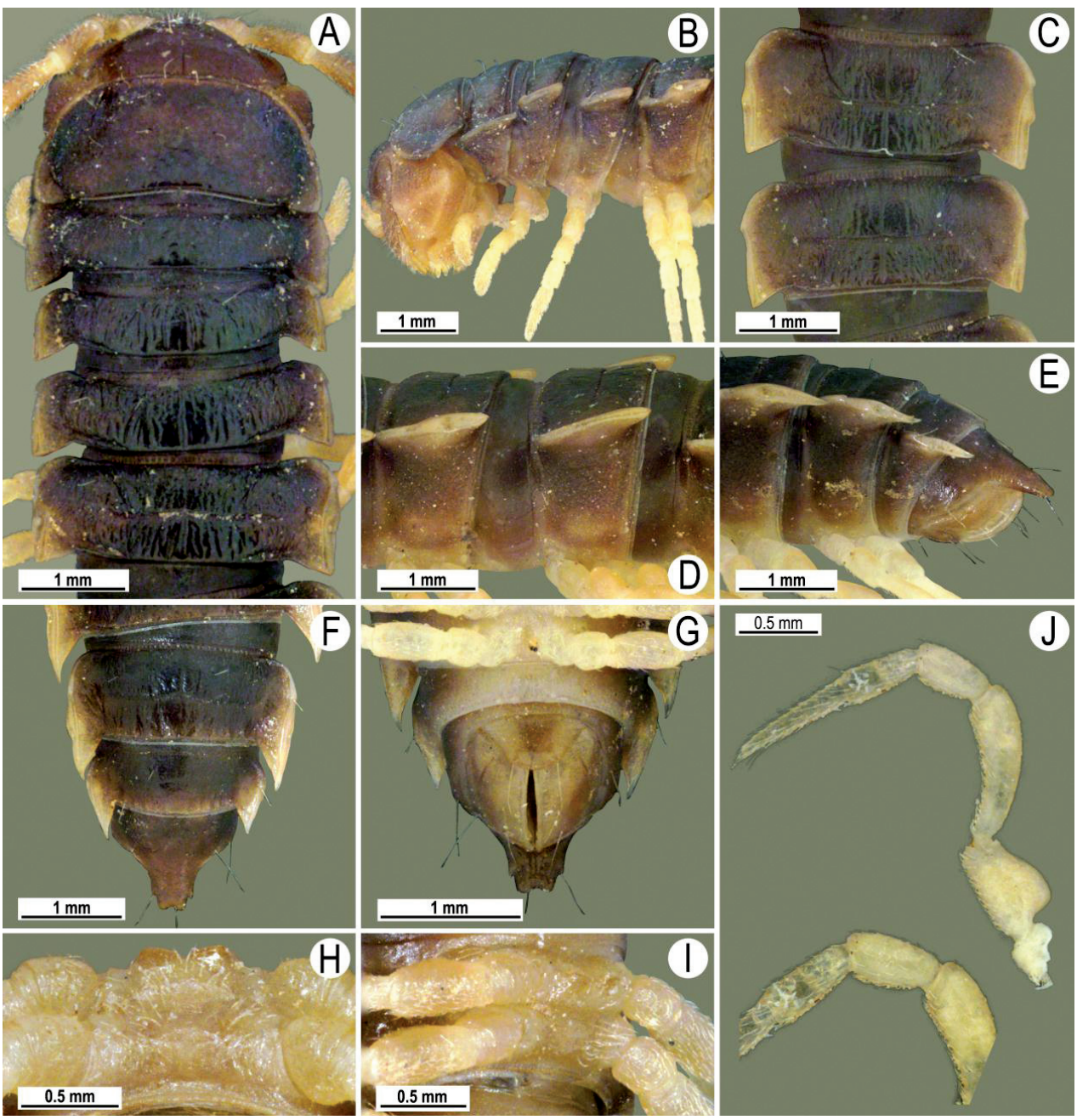

Figure 25. Tylopus jeekeli Golovatch \& Enghoff, 1993, § (A-J). A, B anterior part of body, dorsal and lateral views, respectively. C, D segments 10 and 11 , dorsal and lateral views, respectively. E, F, G posterior part of body, lateral, dorsal and ventral views, respectively $\mathbf{H}, \mathbf{I}$ sternal cones between coxae 4 , subcaudal and sublateral views, respectively J midbody leg.

\section{Tylopus rugosus Golovatch \& Enghoff, 1993}

Figs 31-33

Tylopus rugosus Golovatch \& Enghoff, 1993: 95.

Tylopus rugosus: Enghoff, 2005: 99.

Material: 4 o (CUMZ), Thailand, Chiang Mai Province, Phrao District, Buathong Waterfall forest park, $510 \mathrm{~m}, 19^{\circ} 4^{\prime} 10^{\prime \prime} \mathrm{N}, 99^{\circ} 4^{\prime} 46 " \mathrm{E}, 29.09 .2009$, leg. N. Likhitrakarn. 


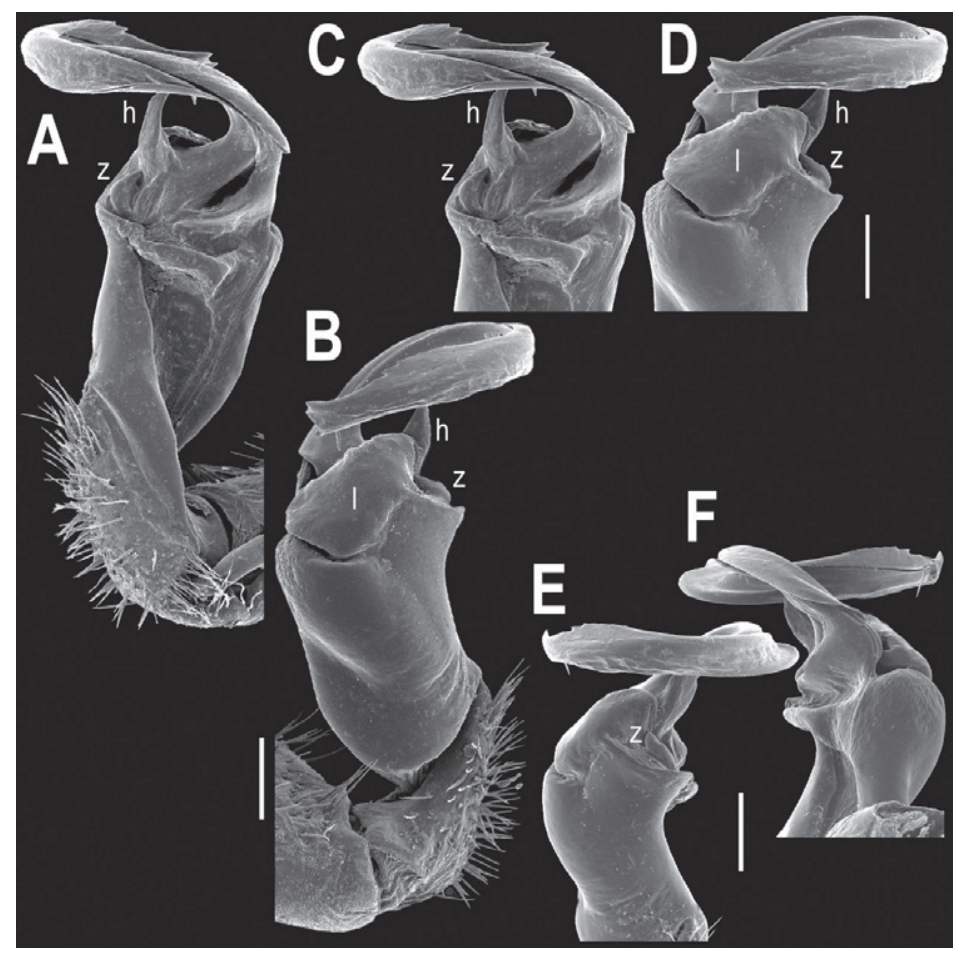

Figure 26. Tylopus jeekeli Golovatch \& Enghoff, 1993, đ̃. A, B right gonopod, mesal and lateral views, respectively C-F distal part of right gonopod, mesal, lateral, suboral and subcaudal views, respectively. Scale bar: $0.2 \mathrm{~mm}$.
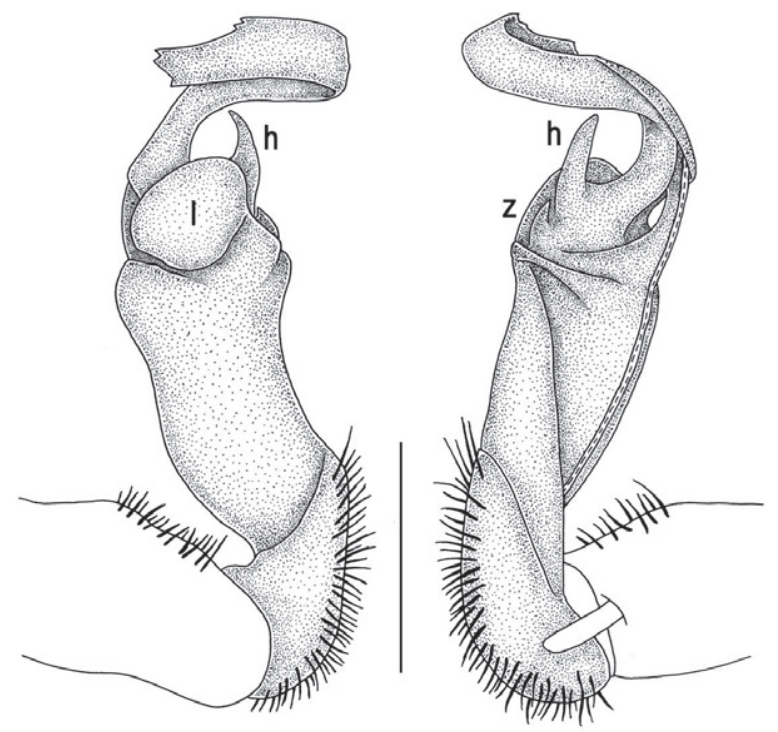

Figure 27. Tylopus jeekeli Golovatch \& Enghoff, 1993, đ. A, B right gonopod, lateral and mesal views, respectively. Scale bar: $0.5 \mathrm{~mm}$. 


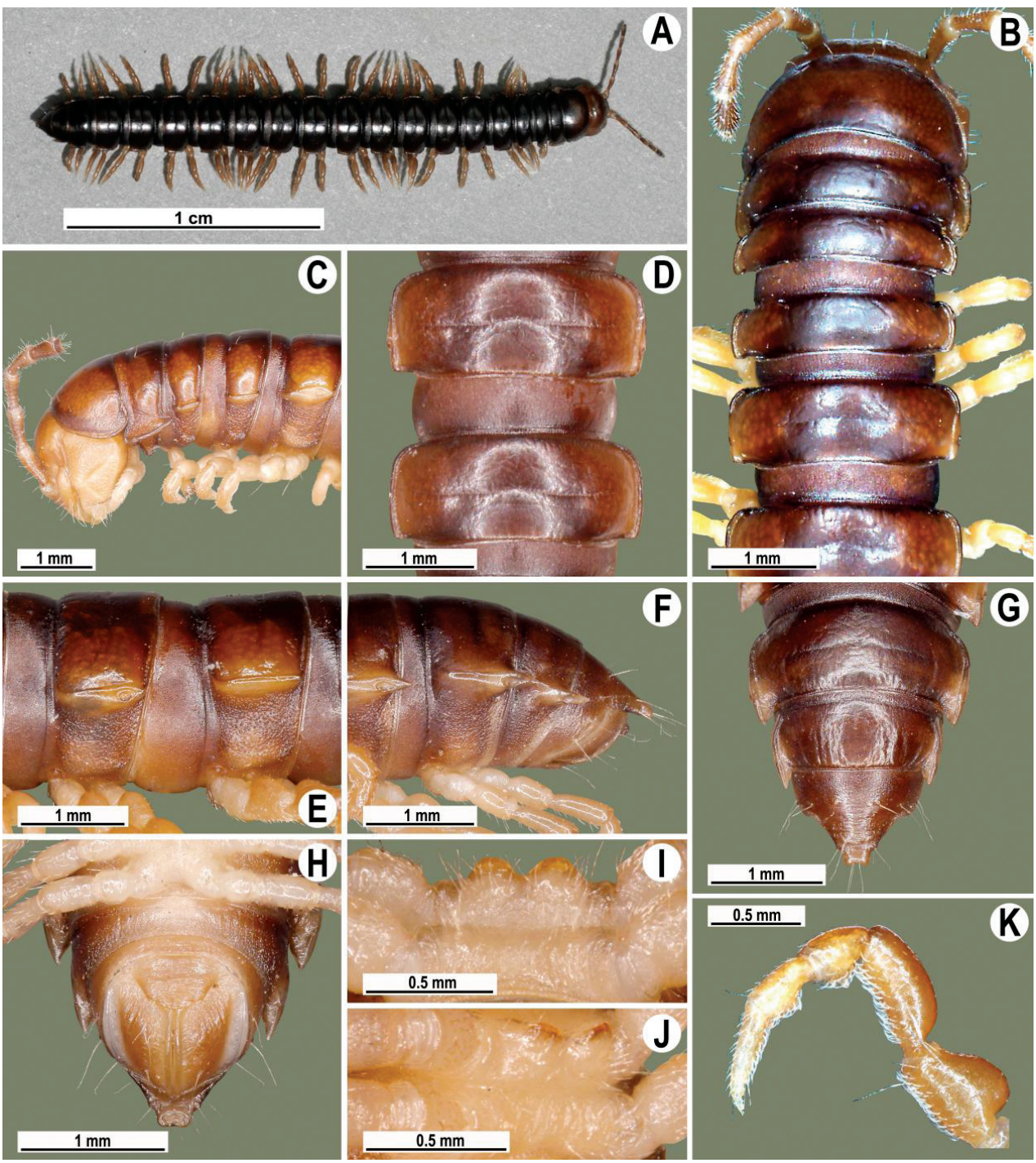

Figure 28. Tylopus prosperus Golovatch \& Enghoff, 1993, ô (A-K). A habitus, live coloration B, C anterior part of body, dorsal and lateral views, respectively $\mathbf{D}, \mathbf{E}$ segments 10 and 11, dorsal and lateral views, respectively $\mathbf{F}, \mathbf{G}, \mathbf{H}$ posterior part of body, lateral, dorsal and ventral views, respectively $\mathbf{I}, \mathbf{J}$ sternal cones between coxae 4, subcaudal and sublateral views, respectively $\mathbf{K}$ midbody leg.

Remarks. This near-topotypic material fully agrees with the original description (Golovatch and Enghoff 1993), showing no evident variation in peripheral and gonopod structure (Figs 31-33). 


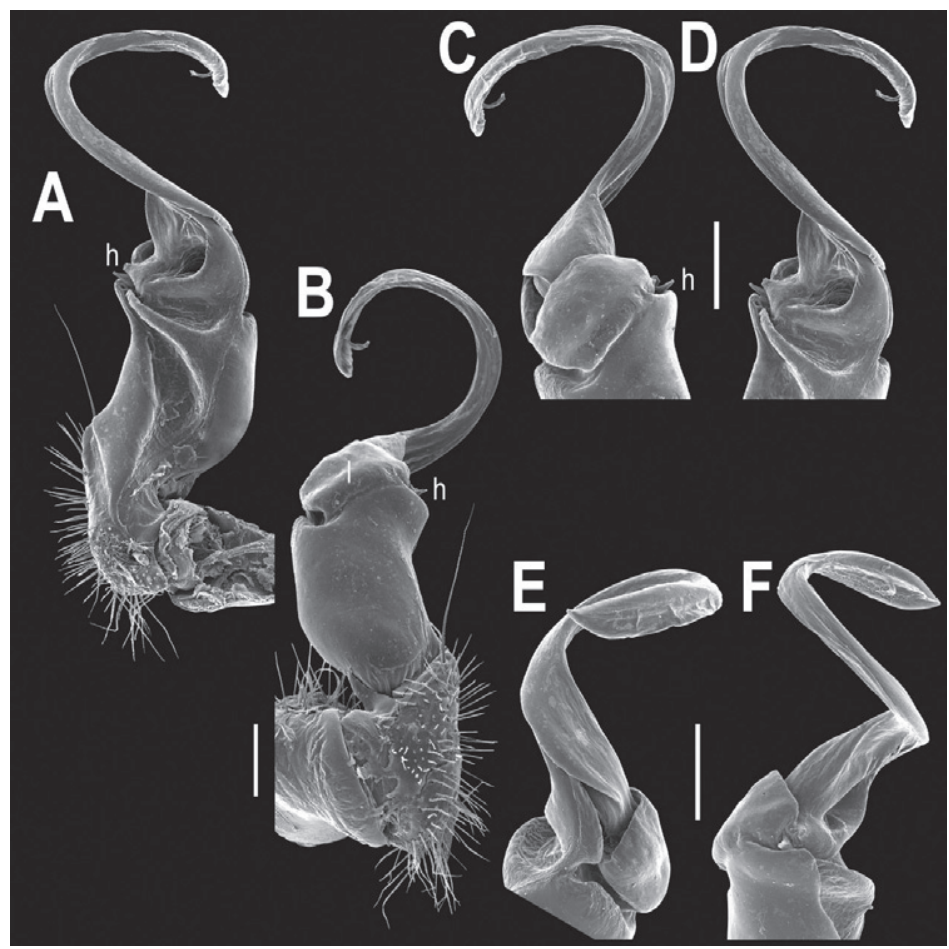

Figure 29. Tylopus prosperus Golovatch \& Enghoff, 1993, §. A, B right gonopod, mesal and lateral views, respectively C-F distal part of right gonopod, sublateral, mesal, suboral and subcaudal views, respectively. Scale bar: $0.2 \mathrm{~mm}$.
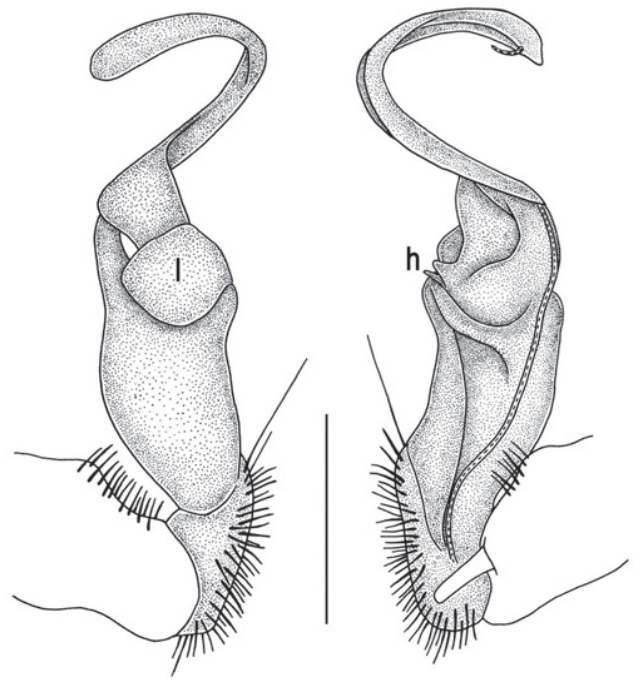

Figure 30. Tylopus prosperus Golovatch \& Enghoff, 1993, đ. A, B right gonopod, lateral and mesal views, respectively. Scale bar: $0.5 \mathrm{~mm}$. 


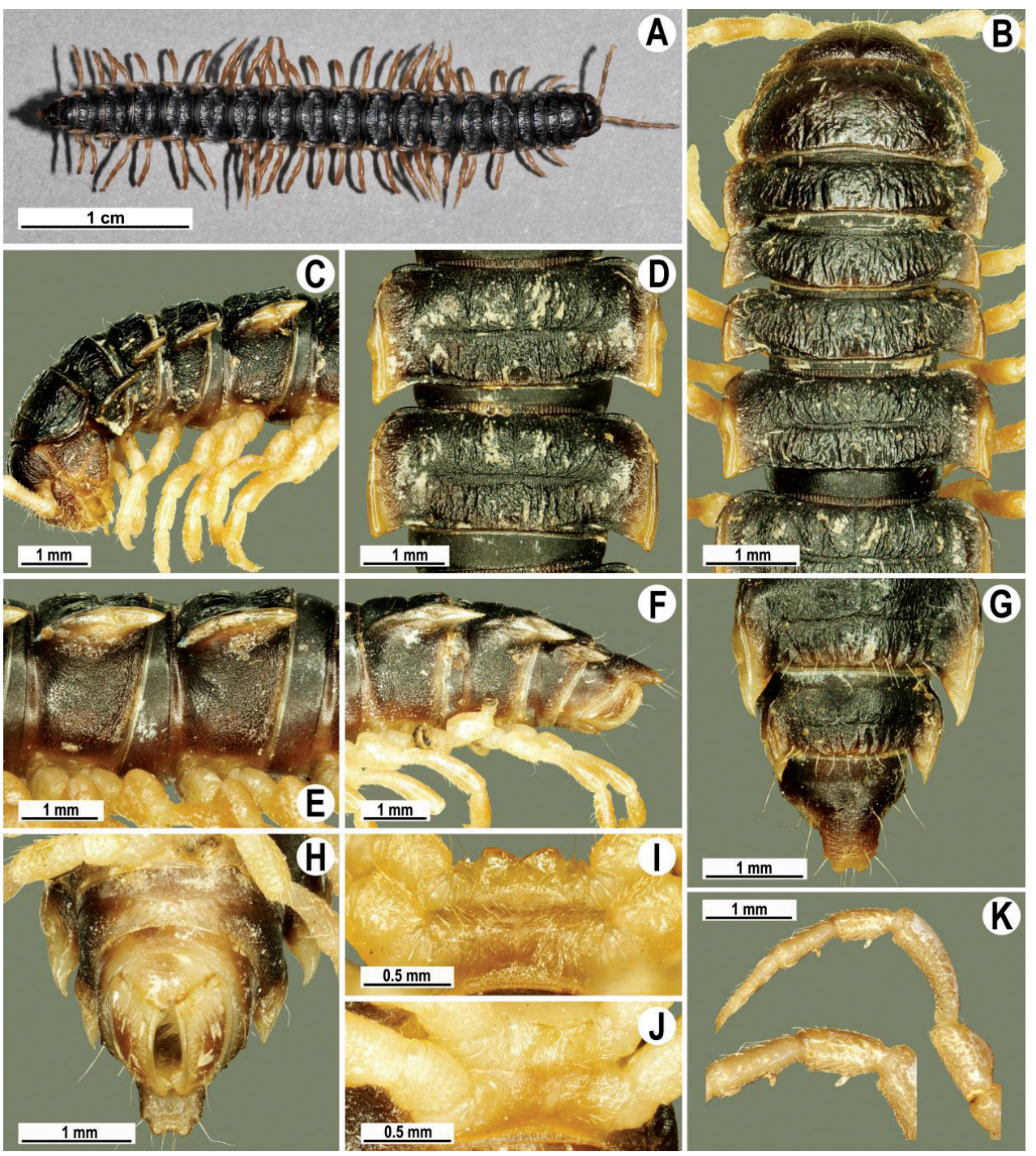

Figure 3 I. Tylopus rugosus Golovatch \& Enghoff, 1993, §̂(A-K). A habitus, live coloration B, C anterior part of body, dorsal and lateral views, respectively $\mathbf{D}$, E segments 10 and 11, dorsal and lateral views, respectively $\mathbf{F}, \mathbf{G}, \mathbf{H}$ posterior part of body, lateral, dorsal and ventral views, respectively $\mathbf{I}, \mathbf{J}$ sternal cones between coxae 4, subcaudal and sublateral views, respectively $\mathbf{K}$ midbody leg.

Tylopus perarmatus Hoffman, 1973

Figs 34-38

Tylopus perarmatus Hoffman, 1973: 372.

Tylopus perarmatus: Golovatch \& Enghoff, 1993: 106.

Tylopus perarmatus: Enghoff, 2005: 99. 


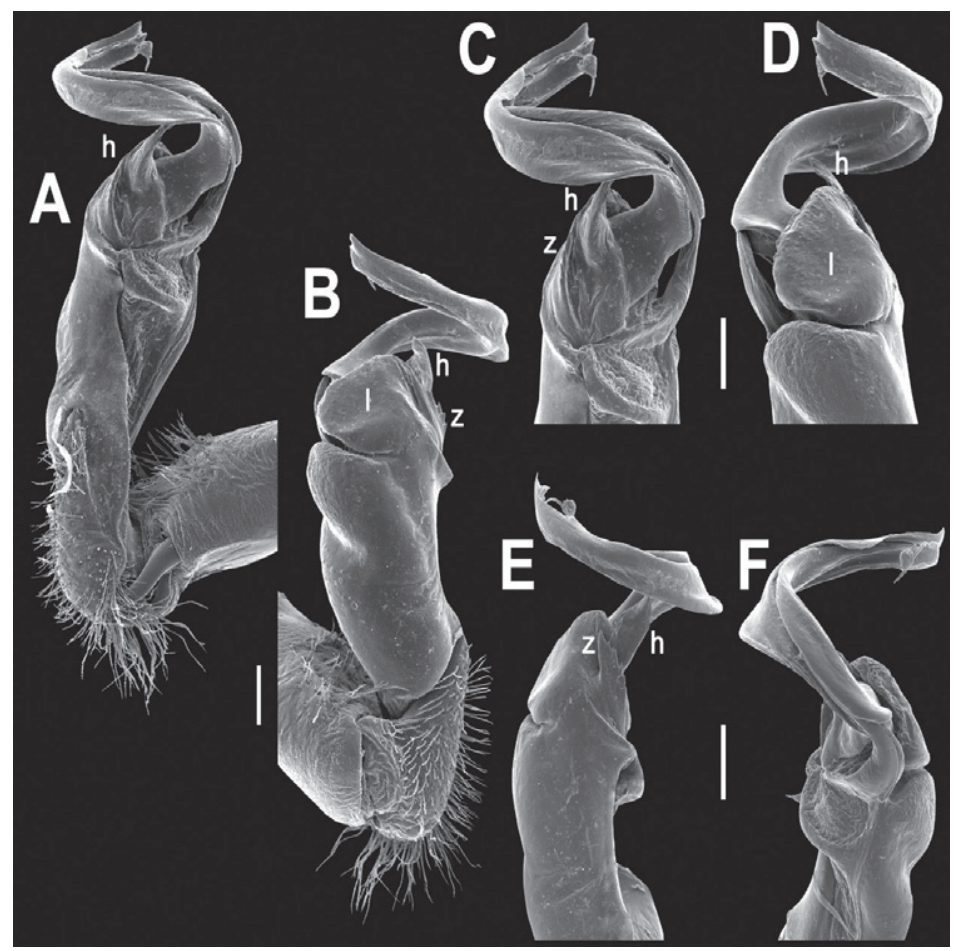

Figure 32. Tylopus rugosus Golovatch \& Enghoff, 1993, ô. A, B right gonopod, mesal and lateral views, respectively C-F distal part of right gonopod, mesal, lateral, suboral and subcaudal views, respectively. Scale bar: $0.2 \mathrm{~mm}$.
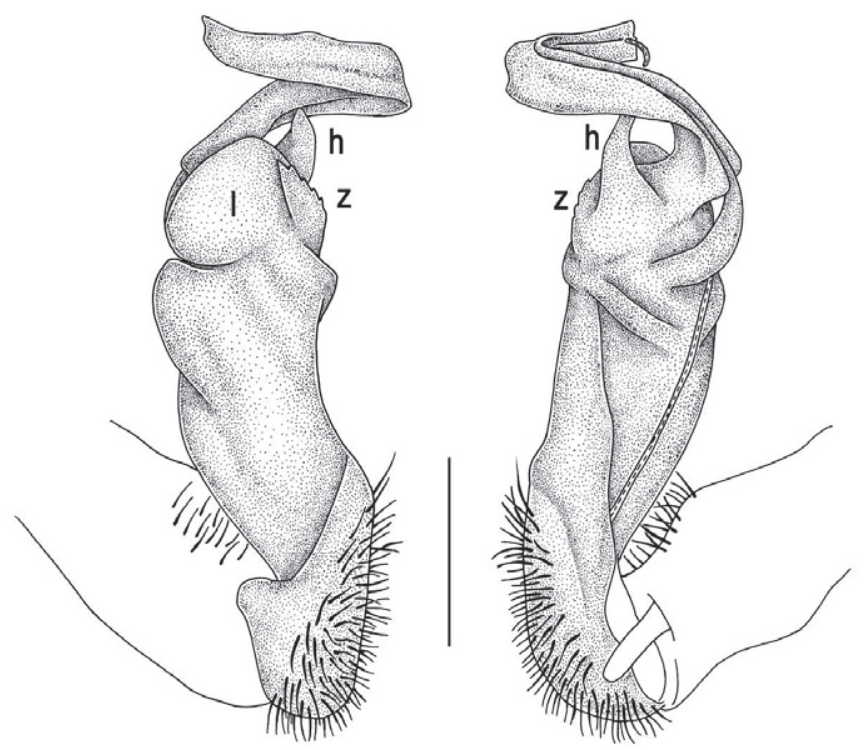

Figure 33. Tylopus rugosus Golovatch \& Enghoff, 1993, ô. A, B right gonopod, lateral and mesal views, respectively. Scale bar: $0.5 \mathrm{~mm}$. 


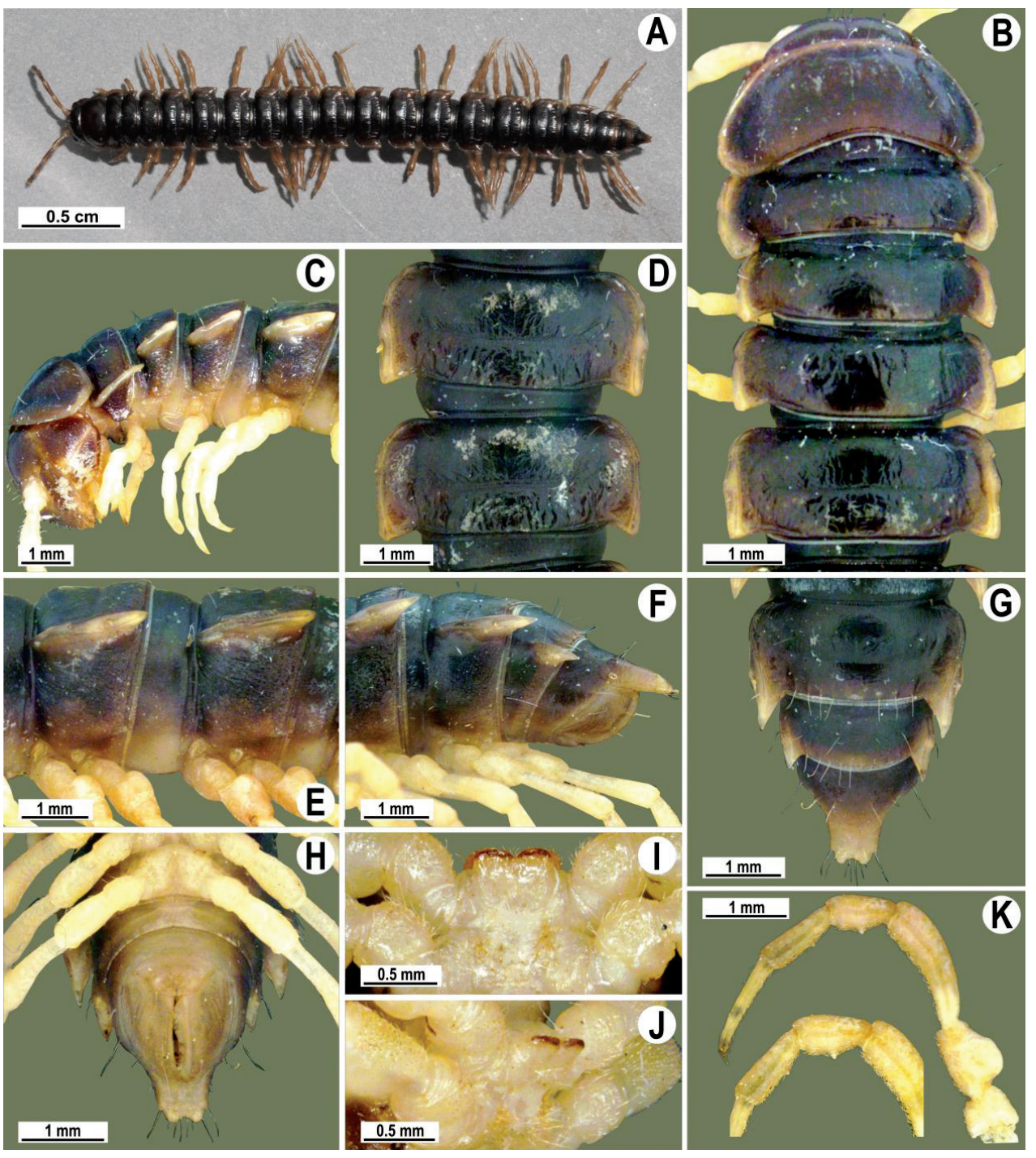

Figure 34. Tylopus perarmatus Hoffman, 1973, đ̂ from Ton Tong Waterfall (A-K). A habitus, live coloration $\mathbf{B}, \mathbf{C}$ anterior part of body, dorsal and lateral views, respectively $\mathbf{D}, \mathbf{E}$ segments 10 and 11, dorsal and lateral views, respectively $\mathbf{F}, \mathbf{G}, \mathbf{H}$ posterior part of body, lateral, dorsal and ventral views, respectively I, J sternal cones between coxae 4, subcaudal and sublateral views, respectively $\mathbf{K}$ midbody leg.

Material: $5 \hat{\jmath}, 3$, 1 juv. (CUMZ), Thailand, Chiang Mai Province, Chom Thong District, Doi Inthanon National Park, Siriphum Waterfall, ca 1320 m, 18³2'49"N, 98³0'57"E, 13.10.2009, leg. S. Panha, J. Sutcharit \& N. Likhitrakarn; 2 o, 2 q (CUMZ), same province, Wiang Kaen District, Doi Phatang, 25.10.2008, leg. S. Panha \& J. Sutcharit; 5 $\widehat{\jmath}, 2$ (CUMZ), Lampang Province, Ngao District, Thum Pha Thai, 23.10.2008, leg. S. Panha, J. Sutcharit \& N. Likhitrakarn; 1 đ, 


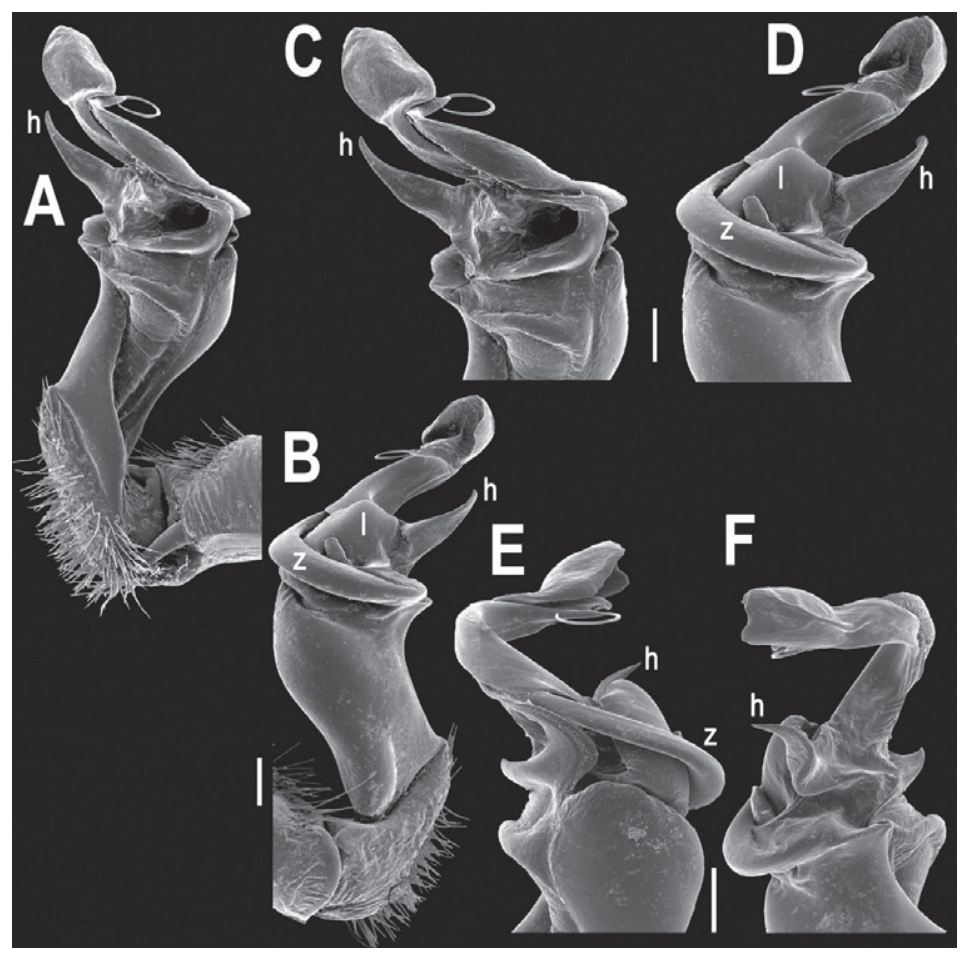

Figure 35. Tylopus perarmatus Hoffman, 1973, ठ̊ from Ton Tong Waterfall. A, B right gonopod, mesal and lateral views, respectively C-F distal part of right gonopod, mesal, lateral, suboral and subcaudal views, respectively. Scale bar: $0.2 \mathrm{~mm}$.
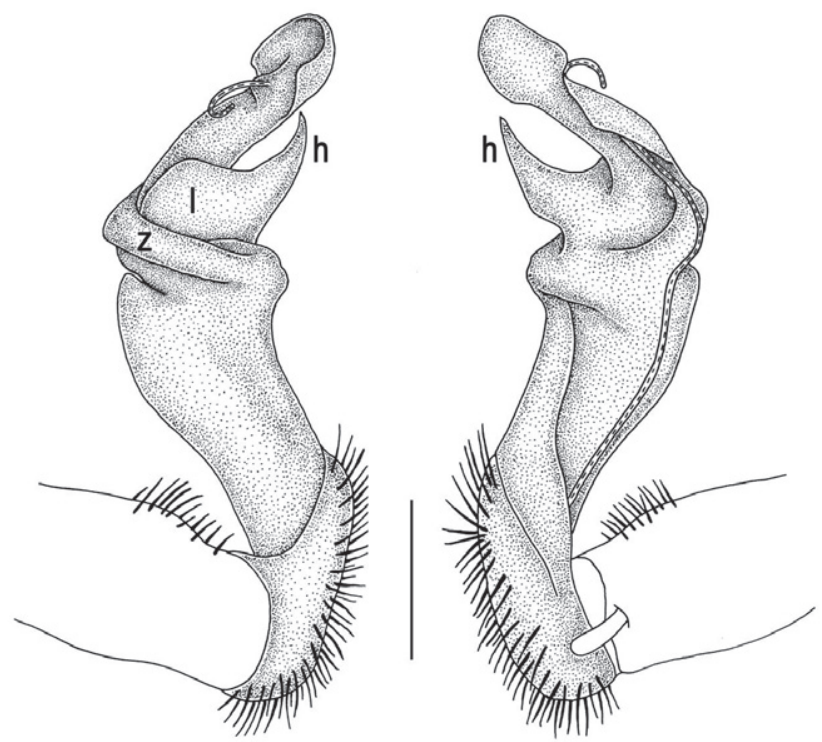

Figure 36. Tylopus perarmatus Hoffman, 1973, ठð from Ton Tong Waterfall. A, B right gonopod, lateral and mesal views, respectively. Scale bar: $0.5 \mathrm{~mm}$. 


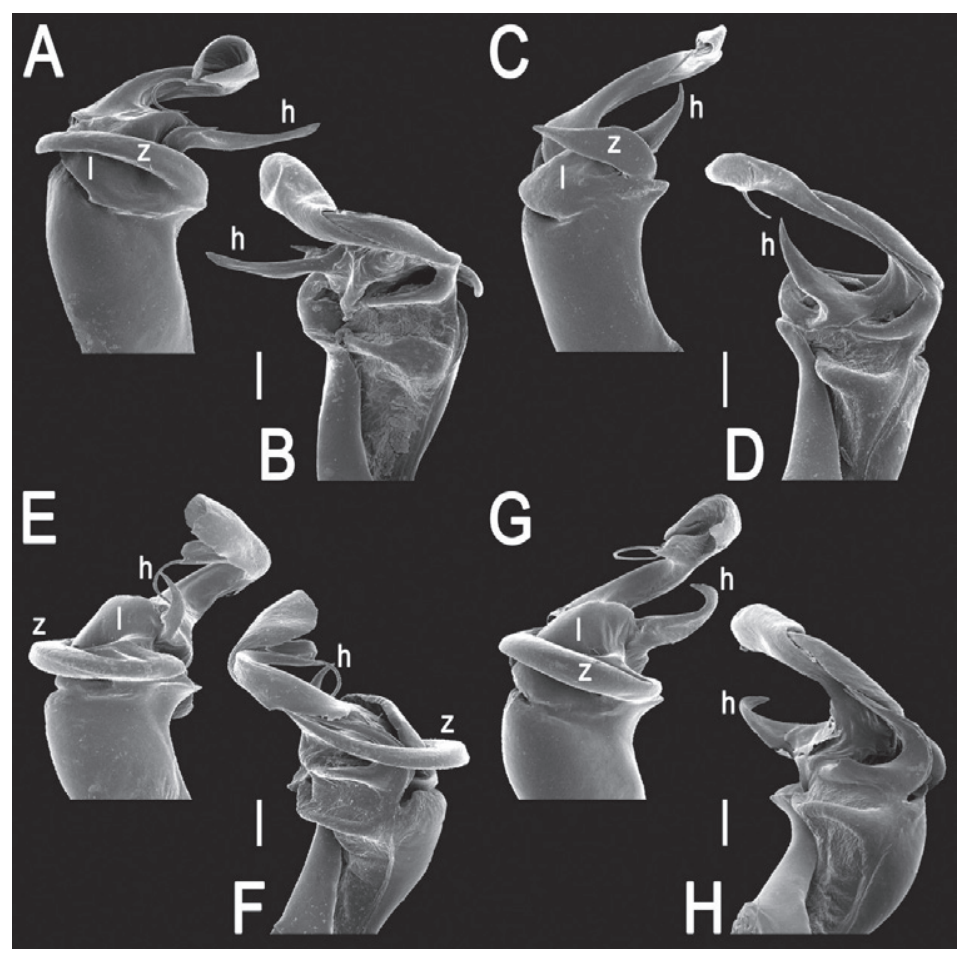

Figure 37. Tylopus perarmatus Hoffman, 1973, ठ̊ from Ban Pang Rim Kon (A, B), ð̊ from Ton Tong Waterfall $(\mathbf{C}, \mathbf{D})$, ô from Phucheefah $(\mathbf{E}, \mathbf{F})$, and $\delta$ from Ton Tong Waterfall $(\mathbf{G}, \mathbf{H})$. A-H distal part of right gonopod, lateral, mesal, lateral, mesal, lateral, mesal, lateral, and mesal views, respectively. Scale bar: $0.2 \mathrm{~mm}$.

1 ㅇ (CUMZ), Chiang Rai Province, Mueang Chiang Rai District, Ban Pang Rim Kon, 10.07.2006, leg. S. Panha; 1 o (CUMZ), same province, Thoeng District, Phucheefah, 10.07.2006, leg. S. Panha \& J. Sutcharit; $2 \hat{\delta}, 1$ q (CUMZ), same province, Wiang Kaen District, Doi Pha Tang, 10.07.2006; 1 ઈ, 2 q (CUMZ), Phayao Province, Chiang Kham District, Nam Min Waterfall, 23.10.2008, leg. S. Panha \& J. Sutcharit; 2 $\widehat{T}, 2$ ㅇ (CUMZ), Phrae Province, Rong Kwang District, Tham Pha Nang Khoi, ca 280 m, $18^{\circ} 22^{\prime} 10^{\prime \prime N}, 100^{\circ} 21^{\prime} 12^{\prime \prime E}, 9.10 .2009$, leg. S. Panha, J. Sutcharit \& N. Likhitrakarn; 2 ô, 2 ㅇ (CUMZ), same locality, 29.09.2010, leg. J. Sutcharit \& P. Pimvichai; 9 O, 6 q, 2 juv. (CUMZ), Nan Province, Pua District, Ton Tong Waterfall, ca $1130 \mathrm{~m}, 19^{\circ} 12^{\prime} 36 " \mathrm{~N}, 101^{\circ} 4^{\prime} 14 " \mathrm{E}, 10.10 .2009$, leg. S. Panha, J. Sutcharit \& N. Likhitrakarn.

Remarks. This species has long been known as perhaps the most widespread and common congener in northern Thailand, also showing considerable variation both in body texture and gonopod structure (Golovatch and Enghoff 1993). The new samples add to this variation in the gonopods often with spine $\mathbf{h}$ rather narrow and spiniform to broadly denti- or lobiform, and spine $\mathbf{z}$ nearly straight to strongly unciform (Figs 34-38). 


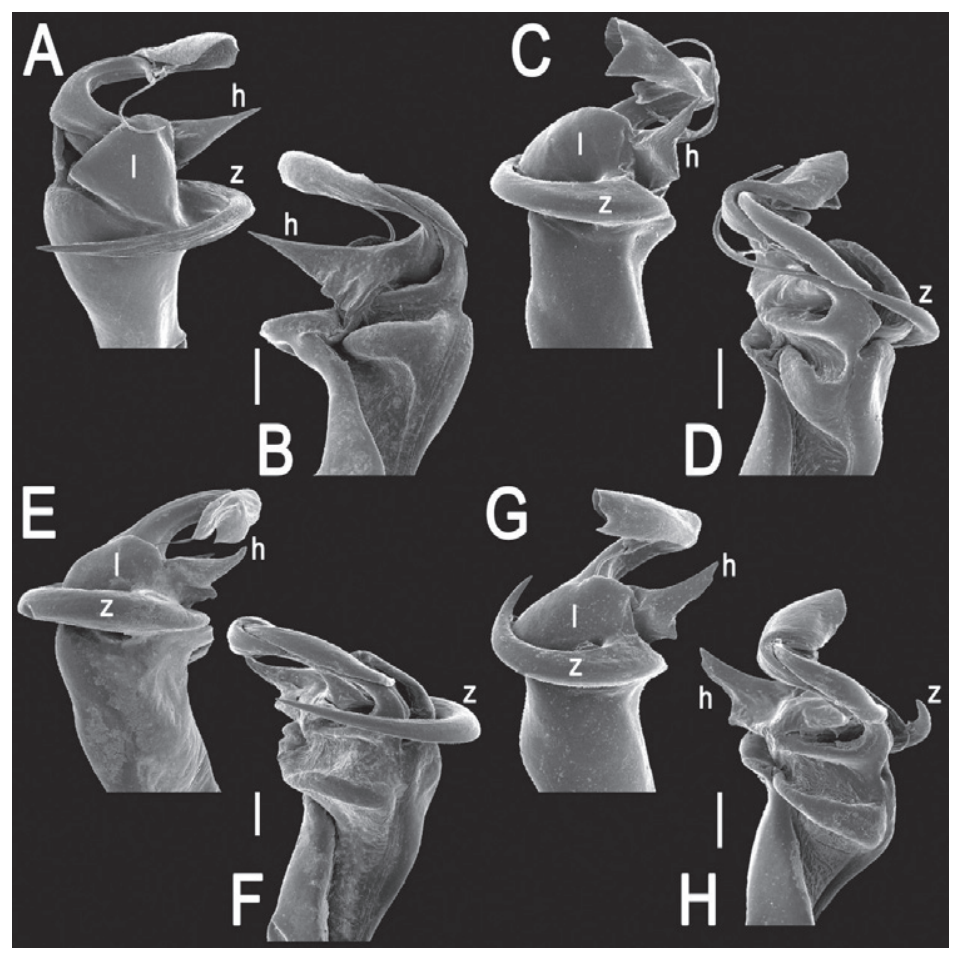

Figure 38. Tylopus perarmatus Hoffman, 1973, ô from Siriphum Waterfall (A, B), ô from Thum Pha Thai $(\mathbf{C}, \mathbf{D})$, $\delta$ from Tham Pha Nang Khoi (E, F), and $\delta$ from Thum Pha Thai $(\mathbf{G}, \mathbf{H})$. A-H: distal part of right gonopod, lateral, mesal, lateral, mesal, lateral, mesal, lateral, and mesal views, respectively. Scale bar: $0.2 \mathrm{~mm}$.

\section{A key to species of Tylopus (based chiefly on $\precsim$ )}

1 Most $\widehat{\jmath}$ prefemora evidently swollen laterally (Figs $1 \mathrm{~K}, 4 \mathrm{~J}, 7 \mathrm{~K}, 10 \mathrm{~K}, 13 \mathrm{~K}$,

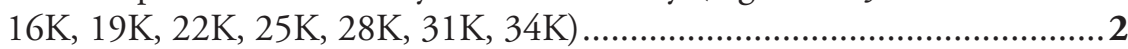

- $\quad$ All $\delta$ prefemora normal, not bulged laterally..........................................25

2 Surface of metaterga virtually smooth, at best extremely faintly rugulose in certain places and/or with a few barely traceable (setiferous) tubercles near caudal margin (setae mostly broken off) ......................................... 3

- $\quad$ Surface of metaterga mostly rugulose to coarsely rugose/tuberculate

3 Paraterga moderately developed (Fig. 28A-G), ratio of $\lesssim$ midbody prozonite to metazonite width ca 1:1.15. Transverse sulcus on metaterga starting from segment 5 , but fully developed and reaching base of paraterga only from segment 6. Calluses without incisions (Fig. 28A-G). Gonopod solenophore particularly slender (Figs 29, 30)

- $\quad$ Paraterga relatively well-developed, radio of $\lambda$ midbody prozonite to metazonite width over 1:1.2. Transverse sulcus on metaterga starting from segment 4 or 5 , always fully developed and reaching base of paraterga on segment 5 ......4 
Calluses without incisions. Gonopod postfemoral lobe 1 much broader than long; area basal to $\mathbf{1}$ delimited by a distinct cingulum

T. magicus Calluses mostly with 1-2 incisions. Gonopod postfemoral lobe $\mathbf{1}$ either as long as broad or longer; no cingulum basal to $\mathbf{1}$. Metatergal surface entirely smooth, polished, without tubercles. Midline wanting. Pleurosternal carinae relatively weak, as small teeth only on a few anteriormost segments; $\widehat{\jmath}$ legs without adenostyles (= tubercles). Gonopods with three rather small, spiniform processes near base of lobe $\mathbf{1}$.

T. mutilatus Metaterga at best only very faintly rugulose near waist, near sulcus and/or at base of paraterga, with 2-3 weak, oblong tubercles near rear margin. Midline mostly traceable at least on anterior halves of metaterga. Pleurosternal carinae more strongly developed; most $\widehat{\jmath}$ postfemora and tibiae tuberculiferous. Gonopods with only two larger outgrowths near base of lobe $\mathbf{l}$ T. similirugosus Metaterga without evident setiferous tubercles, only sometimes with very small, rudimentary wrinkles or knobs

Body larger: 38-42 mm long, 2.8-3.8 and 4.3-5.0 mm wide on pro- and metaterga, respectively. Gonopod with a short spiniform process $\mathbf{h}$, a basally only poorly delimited lobe $\mathbf{1}$, and a small lobiform process $\mathbf{z}$ (Figs 5, 6)....

T. grandis sp. $\mathrm{n}$.

Gonopod process $\mathbf{h}$ subflagelliform, process $\mathbf{m}$ extremely long and prominent (Figs 8, 9)

$\widehat{o}$ legs shorter, ca 1.2-1.3 times as long as midbody height (Fig. 10K). Gonopod lobe 1 velum-shaped and supplied with two denticles; spine $\mathbf{z}$ short and knife-shaped while spine $\mathbf{h}$ rudimentary (Figs 11, 12). $\widehat{0}$ legs longer, ca 1.6-1.7 times as long as midbody height (Fig. 13K). Gonopod spine $\mathbf{z}$ small, placed closer to base of spine $\mathbf{h}$ (Figs 14, 15)...

T. parajeekeli sp. $\mathrm{n}$.

11 Most metaterga with a pattern of $2+2$ and $2+2$ setiferous tubercles in two rows, rear row somewhat less strongly developed than fore one

T. doriae Most metaterga with rear row of setiferous tubercles or wrinkles more strongly developed than fore row, the latter (next to) wanting

Transverse sulcus on metaterga starting from segment 4, either fully or almost fully developed there, always fully developed from segment 5

13 Transverse sulcus fully developed and reaching base of paraterga already from segment 4. Gonopod tooth $\mathbf{z}$ at base of lobe $\mathbf{l}$ coarsely serrate along proximal margin 

either devoid of serration or serrate along distal margin

Transverse sulcus fully developed only from segment 5 . Gonopod tooth $\mathbf{z}$ 14 Paraterga 2 caudolaterally rather broadly rounded. Gonopod relatively simple, process $\mathbf{h}$ poorly developed, no additional outgrowths near base.

T. affinis

Paraterga 2 caudally pointed. Gonopods more complex

Coloration dark brown, without cingulate pattern. Sternal lamina between $\delta$ coxae 4 low and distinctly bimodal (Fig. 31I, J). Gonopods (Figs 32, 33) with tooth $\mathbf{z}$ prominent and serrate along distal margin T. rugosus Coloration pale, with a cingulate pattern. Sternal lamina between $\delta$ coxae 4 high, subquadrate. Gonopod tooth $\mathbf{z}$ smaller and spiniform .....T. semirugosus Paratergal corner protruding caudad beyond rear contour only from segment 15 , being obtusangular or subrectangular and lying more or less within the contour until segment 14

T. hilaroides Paratergal corner protruding caudad before segment 14, mostly pointed....17 Pattern of tergal setation on segments 18 and/or 19: $2+2$ and 5+5 in two rows

Pattern of tergal setation at least on segments 5-19: $2+2$ and $4+4$ in two rows

Pattern of tergal setation $2+2$ and $5+5$ on both segments 18 and 19. Paraterga 2 caudally pointed. Epiproct with pre-apical incisions very close to apical knobs. Sternal lamina between $\delta$ coxae 4 an unusually low, even ridge. Adenostyles on midbody $\widehat{o}$ postfemora and, to a lesser extent, tibiae exceptionally prominent.

T. poolpermorum Pattern of tergal setation $2+2$ and $5+5$ on segment 19. Paraterga 2 more or less narrowly rounded. Pre-apical incisions on epiproct better removed from tip. Sternal lamina between $\widehat{\partial}$ coxae 4 concave medially. Ventral adenostyles on $\sigma^{\lambda}$ legs less prominent. Body smaller: width ca $2.0 \mathrm{~mm}$. Sternal lamina between $\hat{\delta}$ coxae 4 as a pair of separate, setiferous tubercles (Fig. 22I, J). Ventral adenostyles on $\delta$ legs almost missing (Fig. 22K). Gonopods without any outgrowth near base of process $\mathbf{h}$ (Figs 23, 24)

T. haplorugosus Body larger: width over $3.0 \mathrm{~mm}$. Sternal lamina between ${ }^{\lambda}$ coxae 4 single. Ventral adenostyles on $\widehat{o}$ legs more prominent. Gonopod with a spine near base of process $\mathbf{h}$ 20 Sternal lamina between ô coxae 4 high, emarginate (Fig. 16I, J). Adenostyles on $\widehat{o}$ postfemora and tibiae well-developed (Fig. 16K). Gonopods rather simple, spine $\mathbf{z}$ inconspicuous (Figs 17, 18) T. allorugosus Sternal lamina between $\hat{\sigma}$ coxae lower, slightly concave. Adenostyles on $\widehat{\delta}$ postfemora and tibiae less strongly developed. Gonopods more complex, spine $\mathbf{z}$ long and large (Figs 35-38).

T. perarmatus Paraterga 2 pointed caudally. Sternal lamina between $\widehat{\partial}$ coxae 4 exceptionally densely setose, low, concave ventrally (Fig. 25I, J). Gonopods with a medi- 
um-sized process $\mathbf{h}$, and a smaller lobular $\mathbf{z}$ at base of $\mathbf{h}$ (Figs 26, 27)

T. jeekeli

Paraterga 2 more or less narrowly rounded caudally. Sternal lamina between $\widehat{c}$ coxae 4 higher and less strongly setose. Gonopod outgrowths $\mathbf{h}$ and $\mathbf{z}$ either almost wanting or very large Sternal lamina between $\sigma^{\lambda}$ coxae 4 with a straight ventral margin. Pleurosternal carinae poorly developed, in $\widehat{\sigma}$ slightly projecting caudad beyond rear margin only until segments $8-10$

Sternal lamina between $\widehat{\jmath}$ coxae 4 slightly concave ventrally. Pleurosternal carinae better developed, in $\widehat{\sigma}$ slightly projecting caudad beyond rear margin at least till segment 15 .

Body smaller: width up to 3.1-3.2 mm. Mid-dorsal line very clear on both halves of metaterga. Gonopods relatively simple, with both $\mathbf{h}$ and $\mathbf{z}$ almost wanting.

T. boffmani

Body larger: width 4.0-5.3 mm. Mid-dorsal line not so well-developed at least on rear halves of metaterga. Gonopods more complex, with both $\mathbf{h}$ and $\mathbf{z}$ very conspicuous

T. baenzigeri Metatergum 19 slightly rugulose posteriorly. Calluses on segment 2 with three, on following paraterga with two, incisions. Gonopods extremely complex, with numerous spiniform outgrowths....

T. perplexus Metatergum 19 entirely smooth. Calluses with two and three incisions on poreless and poriferous paraterga, respectively. Gonopod less strongly differentiated.

T. amicus Either most of $\widehat{\gamma}$ sterna with oblique tubercles or spines, or only anterior sterna with small cones near coxae ....................................................26 Neither spines nor tubercles on $\delta$ sterna.............................................28 Only rear sternum on most of $\widehat{\partial}$ segments with a pair of small spines. Metaterga mostly with $2+2$ and $3+3$ setiferous tubercles in two transverse rows. Gonopod process $\mathbf{h}$ and lobe $\mathbf{l}$ relatively well-developed..... T. silvestris Fore and rear sterna of most of $\widehat{\sigma}$ segments with a pair of tubercles and spines, respectively. Fore row of tergal setae not borne on tubercles, rear row on $2+2$ tubercles

Transverse sulcus starting from metatergum 4, fully developed from metatergum 5. $\widehat{o}$ tarsal brushes missing. Northern Vietnam. T. maculatus Transverse sulcus starting from metatergum 3, still underdeveloped on metatergum 4, fully developed from metatergum 5. 0 tarsal brushes present only on a few anteriormost legs. Yunnan, China

T. sinensis Metaterga entirely smooth and polished, devoid of evident tubercles, at best extremely faintly rugulose near transverse sulcus

Metaterga rather clearly rugose/tuberculate/granulate, posterior row of setae at least partly borne on tubercles Transverse sulcus on metaterga starting from segment 4, but fully developed and reaching base of paraterga only from segment 5 . Ventral adenostyles on 
$\widehat{T}$ legs: a distal knob on femur, a distomedial knob on postfemur, and a parabasal knob on both tibia and tarsus.

Transverse sulcus on metaterga starting only from segment 5 . Pattern of $\widehat{\partial}$ leg adenostyles otherwise.

Head a little wider than collum and subequal in width to segment 3 . Paraterga caudally considerably acutangular and beak-shaped only from segment 14 . Gonopod process $\mathbf{h}$ at about midlength with a strong ventral outgrowth

Head a little narrower than collum and subequal in width to segment 2 . Paraterga caudally beak-shaped already from segment 7 , especially strongly so from segment 12. Gonopod process $\mathbf{h}$ without outgrowth T. crassipes Larger species: body width $3.1 \mathrm{~mm}$. Pattern of tergal setation: $2+2$ and $3+3$ to $6+6$ in two rows, rear row easily traceable due to insertion points. Metaterga very finely rugulose only near transverse sulcus. Epiproct unusually broad. Pads instead of adenostyles on $\widehat{\partial}$ femora, postfemora, tibiae (all distally) and tarsi (almost entirely) Small species: width $1.6 \mathrm{~mm}$. Only a single row of $2+2$ tergal setae. Metaterga entirely smooth. Epiproct not so wide. Adenostyles on ${ }^{\widehat{T}}$ legs present

T. sigma

Metatergal surface polished and smooth except for conspicuous tubercles in two rows

Metaterga at least partly rugulose/rugose to granular; at most one row of tubercles.

33 Paraterga very poorly developed, rounded, low, projecting slightly caudad beyond rear contour like small knobs only on segments 18 and 19. Calluses virtually devoid of incisions. Transverse sulcus on metaterga poorly developed, starting already from segment 2 , although fully developed only from segment 5. A paramedian pair of denticles between $\hat{\delta}$ coxae 5 behind a prominent, subquadrate lamina between $\delta$ coxae 4 . Gonopod process $\mathbf{h}$ entirely missing, lobe $\mathbf{1}$ normal T. strongylosomoides

- $\quad$ Paraterga better developed, protruding caudad beyond rear contour at least from segment 5. Calluses always at least with one lateral incision. Transverse sulcus starting only from segments $3-5$. Dentiform tubercles between $\widehat{\delta}$ coxae 5 missing. Gonopod process $\mathbf{h}$ invariably present, lobe $\mathbf{1}$ with a spine apically .34

34 Paraterga acutangular caudally and pointed beak-like already from collum. Tergal setiferous tubercles: $3+3$ and $5+5$ on segments $16-19$. Adenostyle pattern on $\widehat{O}$ legs: a distal knob on femora and a parabasal knob on most of postfemora, tibiae, and tarsi. Gonopod process $\mathbf{h}$ large, lamellar, sigmoid .....

T. granulatus

- $\quad$ Paraterga acutangular caudally and pointed beak-like only from segment 4. $2+2$ and $4+4$ tergal setiferous tubercles on segments 16-19. Adenostyle pattern on $\hat{\delta}$ legs: a proximal finger-shaped tubercle crowned with a bunch of 
setae only on femora 6,8 , and 9. Gonopod process $\mathbf{h}$ smaller, spiniform T. topali

Transverse sulcus on metaterga starting and fully developed from segment 5 . Ventral adenostyles present on all $\widehat{\sigma}$ podomeres except coxa

Transverse sulcus on metaterga starting from segment 4, but fully developed only from segment 5 . Ventral tubercles only on some of $\bar{\partial}$ telopoditomeres ...

Metaterga rugulose also in front of transverse sulcus, at rear margin with several oblong tubercles. Sternal lamina between $\widehat{o}$ coxae 4 like a pair of setiferous knobs. Neither gonopod lobe $\mathbf{m}$ nor lobe $\mathbf{l}$ spinigerous... T. tamdaoensis Metaterga rugose only behind transverse sulcus, without evident turbercles at rear margin. Sternal lamina between ô coxae 4 single. Both gonopod lobe $\mathbf{m}$ and lobe $\mathbf{l}$ crowned with a spine.

T. nodulipes

37 Metaterga modestly rugulose only near transverse sulcus, posteriorly neither granular nor microtuberculate. Calluses broad. Gonopod process $\mathbf{h}$ simple, high, never particularly coiled; lobe $\mathbf{l}$ very modestly serrate at apex

- $\quad$ Metaterga distinctly rugose-granular/microtuberculate even on fore halves. Calluses narrow. Gonopod process $\mathbf{h}$ better developed and more strongly coiled; lobe $\mathbf{l}$ apically either bare or with a digitiform outgrowth Caudal corner of paraterga pointed from segment 3. Pleurosternal carinae particularly well-developed, surpassing rear contour until segment 16 or 17 . Adenostyles often present on ô prefemora, pattern as in Fig. 19K. Gonopods as in Figs 20, 21

T. degerboelae

- Caudal corners of paraterga mainly narrowly rounded, pointed only from segment 15. Pleurosternal carinae less strongly developed

T. pallidus

39 Coloration dark, brown. Sternal lamina between ${ }^{\lambda}$ coxae 4 like a pair of separate, setiferous tubercles preceded by another pair of very small tubercles between coxae 3. Gonopod with lobe $\mathbf{1}$ devoid of an apical process T. asper

- $\quad$ Coloration uniformly pale. Sternal lamina between $\widehat{\partial}$ coxae 4 single, not accompanied by additional tubercles in front or behind. Gonopod lobe $\mathbf{1}$ with a strong, apical, finger-shaped process.....

40 Mostly $3+3$ tubercles at rear margin of metaterga. Sternal lamina between $\delta$ coxae 4 distinctly emarginate. Larger adenostyles close to midlength on $\widehat{\delta}$ postfemora and tibiae, femora with a distal knob. Gonopod process $\mathbf{h}$ slenderer and shorter, apex of lobule $\mathbf{m}$ not developed into a spine

T. subcoriaceus

- Mostly 4+4 tubercles at rear margin of metaterga. Sternal lamina between $\widehat{\jmath}$ coxae trapeziform. Larger adenostyles on both postfemora and tibiae more distal, femoral knob missing. Gonopod process $\mathbf{h}$ unusually prominent, with a hook at base, apex of lobule $\mathbf{m}$ spiniform T. coriaceus 


\section{Conclusion}

Tylopus appears to be one of the largest millipede genera in Southeast Asia. The genus is best known from Thailand, which has 26 (> 63\%) of the described species. With further progress in our knowledge of the millipede faunas of other, still poorly prospected, mostly neighbouring countries such as Laos, Myanmar, Cambodia and Vietnam, as well as southern China, the total of 41 Tylopus species can readily be expected at least to double. More congeners are likely to be found in Thailand as well. Golovatch and Enghoff (1993) attempted a preliminary phylogenetic analysis of Tylopus based on the 35 species then known, but given the incomplete state of our knowledge of Tylopus, we believe that a new phylogenetic analysis would be premature.

In Thailand, all Tylopus are confined to the northern, mountainous parts of the country (Map). Finding congeners south of Tak Province seems unlikely, but, since Tylopus are known also from all over Vietnam, including the southern parts of the country, this genus is likely to occur at least in the adjacent parts of Cambodia, from where no species have hitherto been recorded. At present the northern range limit of Tylopus lies in Yunnan Province, China, but it seems plausible that many more regions in southern China, even some north of Yunnan, might also prove to support Tylopus species. Since only a few species have been reported from Laos and Myanmar, another considerable increase in the number of congeners is more than likely after further collecting in those countries as well.

Almost all Tylopus species are confined to forest habitats, especially montane ones. Most are local to highly local in distribution. There are only very few relatively widespread congeners, e.g. T. doriae, T. perarmatus or T. degerboelae. At one locality, as many as nine congeners can co-occur, e.g. in Doi Inthanon and Doi Suthep mountains. This remarkable result indicates that many other high- to mid-montane forested areas in Indochina and southern China could support similarly rich faunules of Tylopus.

Within Tylopus sympatric groups, only $T$. degerboelae appears to show a highly extended, almost annual pattern of seasonal activity, judging from the occurrence of adults of both sexes at Doi Inthanon and, especially, Doi Suthep. Adults of the bulk of congeners living at either (four species each) or both (five species) of these mountain ranges tend to be autumnal, their collection being confined to September to November. This probably means that these species represent a single, autumnal phenofauna. The sole, possibly noteworthy exception is T. asper which has heretofore been found only at Doi Inthanon and only in May. Whether this species represents a different phenofauna or not, remains open to question. Special observations are required to reveal the phenology and breeding seasons of Tylopus at least in northern, mostly montane Thailand. 


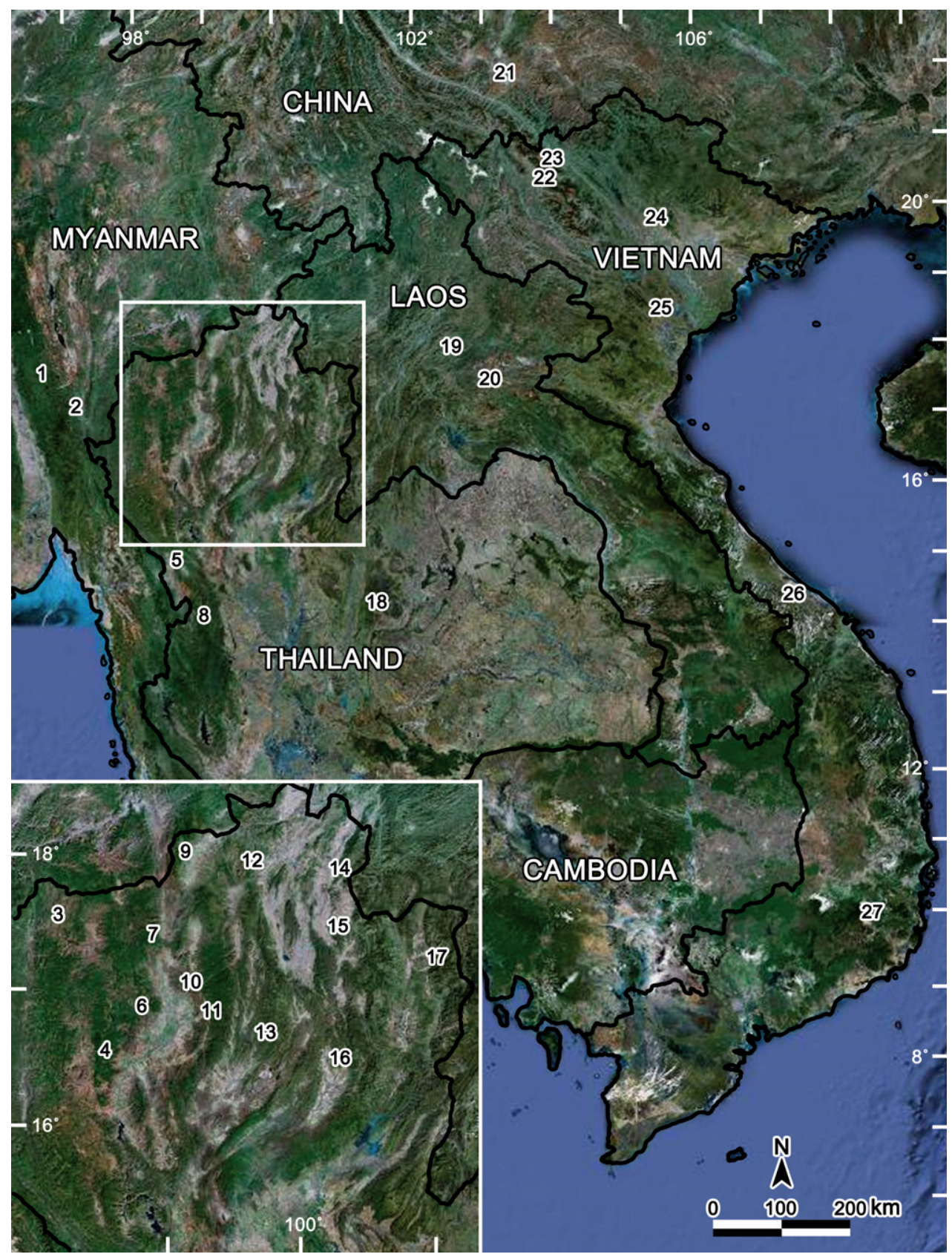


Map Distribution of Tylopus species: 2 species (Myanmar), 26 species (Thailand), 2 species (Laos), 1 species (China), 13 species (Vietnam): I Yado: T. doriae (Pocock, 1895). 2 Village of Thao: T. silvestris (Pocock, 1895). 3 Pha Mon Cave: T. grandis sp. n. 4 Doi Inthanon: T. affinis Golovatch \& Enghoff, 1993, T. allorugosus Golovatch \& Enghoff, 1993, T. asper Golovatch \& Enghoff, 1993, T. degerboelae Golovatch \& Enghoff, 1993,T. haplorugosus Golovatch \& Enghoff, 1993, T. jeekeli Golovatch \& Enghoff, 1993, T. perarmatus Hoffman, 1973, T. prosperus Golovatch \& Enghoff, 1993, T. parajeekeli sp. n. 5 Ban Mussoe: T. semirugosus Golovatch \& Enghoff, 1993. 6 Doi Suthep: T. affinis Golovatch \& Enghoff, 1993, T. allorugosus Golovatch \& Enghoff, 1993, T. baenzigeri Golovatch \& Enghoff, 1993, T. degerboelae Golovatch \& Enghoff, 1993, T. doriae (Pocock, 1895), T. hoffmani Golovatch \& Enghoff, 1993, T. jeekeli Golovatch \& Enghoff, 1993, T. perarmatus Hoffman, 1973, T. similirugosus Golovatch \& Enghoff, 1993, T. subcoriaceus Golovatch \& Enghoff, 1993. 7 Doi Chiang Dao: T. degerboelae Golovatch \& Enghoff, 1993, T. perarmatus Hoffman, 1973, T. rugosus Golovatch \& Enghoff, 1993. 8 Umphang District: T. bispinosus sp. n. 9 Doi Pha Hom Pok: T. amicus Golovatch \& Enghoff, 1993, T. pallidus Golovatch \& Enghoff, 1993, T. perplexus Golovatch \& Enghoff, 1993, T. poolpermorum Golovatch \& Enghoff, 1993, T. extremus sp. n. 10 BuathongWaterfall: T. rugosus Golovatch \& Enghoff, 1993. I I Doi Phatang: T. degerboelae Golovatch \& Enghoff, 1993, T. perarmatus Hoffman, 1973. I 2 Ban Pang Rim Kon: T. perarmatus Hoffman, 1973. 13 Thum Pha Thai: T. perarmatus Hoffman, 1973. 14 Phucheefah: T. perarmatus Hoffman, 1973. 15 Nam Min Waterfall: T. perarmatus Hoffman, 1973. 16 Tham Pha Nang Khoi: T. perarmatus Hoffman, 1973. 17 Ton Tong Waterfall: T. veliger sp. n. 18 Phu Kheio: T. coriaceus Golovatch \& Enghoff, 1993, T. pulvinipes Golovatch \& Enghoff, 1993. 19 Luang Prabang: T. nodulipes (Attems, 1953), T. mutilatus (Attems, 1953). 20 XiengKuang: T. mutilatus (Attems, 1953). 2 I Mengzi County: T. sinensis Golovatch, 1995. 22 Mt Fan-Si-Pan: T. nodulipes (Attems, 1953). 23 O quy ho: T. crassipes Golovatch, 1984, T. maculatus Golovatch, 1984, T. magicus Golovatch, 1984, T. procurvus Golovatch, 1984. 24 Tam Dao: T. strongylosomoides (Korsós \& Golovatch, 1989), T. tamdaoensis Korsós \& Golovatch, 1989. 25 Cuc Phuong Nature Reserve: T. granulatus Golovatch, 1984, T. hilaroides Golovatch, 1984, T. topali Golovatch, 1984. 26 Bana: T. hilaris (Attems, 1937). 27 Peak Langbiang: T. mutilatus (Attems, 1953). 


\section{Acknowledgements}

We would like to extend our deep gratitude to all of the collectors involved, mainly staff of the Animal Systematics Research Unit of Chulalongkorn University, Bangkok. The first author is deeply obliged to the programme Strategic Scholarships for Frontier Research Network for the Joint Ph.D. Program Thai Doctoral degree from the Office of the Higher Education Commission, CHE-RG under the Limestone Biodiversity Project and the BRT Programme (TRF/BIOTECH Thailand Biodiversity Research and Training Program) for their financial support.

\section{References}

Attems C (1937) Myriopoda 3. Polydesmoidea I. Fam. Strongylosomidae. Das Tierreich 68: $1-300$.

Attems C (1953) Myriopoden von Indochina. Expedition von Dr. C. Dawydoff (1938-1939). Mémoires du Muséum national d'Histoire naturelle, N.S., 5A: 133-230.

Enghoff H (2005) The millipedes of Thailand (Diplopoda). Steenstrupia 29(1): 87-103.

Golovatch SI (1984) Contributions to the millipede fauna of Vietnam (Diplopoda) II. Acta Zoologica Hungarica 30: 53-77.

Golovatch SI (1995) On several new or poorly-known Oriental Paradoxosomatidae (Diplopoda, Polydesmida), III. Arthropoda Selecta 4(2): 89-97.

Golovatch SI, Enghoff H (1993) Review of the millipede genus Tylopus, with descriptions of new species from Thailand (Diplopoda, Polydesmida, Paradoxosomatidae). Steenstrupia 19: $85-125$.

Hoffman RL (1973) Descriptions and allocations of new or poorly known genera and species of Paradoxosomatidae from south-eastern Asia (Diplopoda: Polydesmida). Journal of Natural History 7: 361-389.

Korsós Z, Golovatch SI (1989) Addenda to the millipede fauna of Vietnam (Diplopoda). Acta Zoologica Hungarica 35: 211-220.

Pocock RI (1895) The Myriapoda of Burma, Pt. IV. Report upon the Polydesmoidea collected by Sig. L. Fea, Mr. E. W. Oates and others. Annali del Museo Civico di Storia Naturale di Genova, Ser. 2 14: 787-834. 